\title{
Perspectives on Immunotherapy of Metastatic Colorectal Cancer
}

\author{
Yongjiu Dai ${ }^{1+}$, Wenhu Zhao ${ }^{1 \dagger}$, Lei Yue ${ }^{1 \dagger}$, Xinzheng Dai ${ }^{1}$, Dawei Rong ${ }^{1}$, Fan $W^{2}{ }^{2}$, \\ Jian $\mathrm{Gu}^{1 *}$ and Xiaofeng Qian ${ }^{1 *}$ \\ 1 Hepatobiliary/Liver Transplantation Center, First Affiliated Hospital, Nanjing Medical University, Nanjing, China, ${ }^{2}$ Department \\ of General Surgery, Nanjing First Hospital, Nanjing Medical University, Nanjing, China
}

\section{OPEN ACCESS}

Edited by:

Liliana Belgioia,

Università di Genova, Italy

Reviewed by:

Kristen Spencer,

Rutgers Cancer Institute of New

Jersey, United States

Roberto Murialdo,

San Martino Hospital (IRCCS), Italy

*Correspondence:

Xiaofeng Qian

qianxiaofeng@njmu.edu.cn

Jian Gu

jiangu0304@163.com

${ }^{+}$These authors have contributed equally to this work and share first authorship

Specialty section:

This article was submitted to Gastrointestinal Cancers,

a section of the journal

Frontiers in Oncology

Received: 10 February 2021 Accepted: 17 May 2021

Published: 09 June 2021

Citation:

Dai Y, Zhao W, Yue L, Dai X, Rong D,

Wu F, Gu J and Qian X (2021)

Perspectives on Immunotherapy of

Metastatic Colorectal Cancer.

Front. Oncol. 11:659964.

doi: 10.3389/fonc.2021.659964
Colorectal cancer, especially liver metastasis, is still a challenge worldwide. Traditional treatment such as surgery, chemotherapy and radiotherapy have been difficult to be further advanced. We need to develop new treatment methods to further improve the poor prognosis of these patients. The emergence of immunotherapy has brought light to mCRC patients, especially those with dMMR. Based on several large trials, some drugs (pembrolizumab, nivolumab) have been approved by US Food and Drug Administration to treat the patients diagnosed with dMMR tumors. However, immunotherapy has reached a bottleneck for other MSS tumors, with low response rate and poor PFS and OS. Therefore, more clinical trials are underway toward $\mathrm{mCRC}$ patients, especially those with MSS. This review is intended to summarize the existing clinical trials to illustrate the development of immunotherapy in $\mathrm{MCRC}$ patients, and to provide a new thinking for the direction and experimental design of immunotherapy in the future.

Keywords: colorectal cancer, liver metastasis, deficient DNA mismatch repair, immunotherapy

immune checkpoint inhibitors, vaccine, adoptive cellular immunotherapy

\section{INTRODUCTION}

Colorectal cancer (CRC) has received a lot of attention and research due to its high incidence $(10.2 \%)$ as well as high fatality rate $(9.2 \%)$ among tumors worldwide (1). Because its early clinical symptoms are atypical and not obvious, CRC is often ignored, leading to delayed diagnosis and treatment. To make the matter worse, approximately $15 \%$ of patients had already developed liver metastases at the time of the diagnosis and nearly half of patients progressed to liver metastasis later (2). CRC patients with limited liver metastases lesions may be cured by surgical resection (3). However, a majority of patients are not suitable for surgery due to the following reasons, such as bone or brain metastasis, coexisting systemic diseases, or insufficient residual liver volume (4).

This leads to the need for other novel therapies to improve the poor clinical outcomes of mCRC patients who are not eligible for surgical excision. Chemotherapy, radiotherapy, emerging molecular targeted therapies and combination therapy have demonstrated efficacy for some patients in numerous clinical trials and some of them have been approved for clinical use (5). Among them, the more noteworthy is the emergence of various immunotherapies. Immunotherapies mainly consist of immune checkpoint inhibitors (ICIs), adoptive cellular immunotherapy (ACI) and cancer vaccines. The principle of immunotherapy is to enhance or weaken the function of various immune cells (T cells, NK cells, macrophages, myeloid-derived suppressor cells) to achieve anti-tumor effect (6). These therapies, especially ICIs (anti-PD-1; anti-PD-L1; anti-CTLA-4), have been shown to be 
effective in patients with CRC that are mismatch repair deficient (dMMR). In other words, immunotherapies including ICIs have a limited effect on those patients with pMMR tumors. More than that, immunotherapy has also been challenged by the increasing discovery of resistance due to mutations and other causes, and the suboptimal stratification of patients by MMR status. This makes immunotherapy combined with chemotherapy and radiotherapy especially molecular targeted therapy get more and more attention and research.

The review aims to expound the rationality and feasibility of the use of immunotherapy in clinical practice by summarizing the existing evidence. Based on an updated analysis of the existing literature, as well as expected results from ongoing and planned clinical trials, we discuss practical strategies for future research targeting novel potential immunotherapies and discuss current barriers.

\section{RATIONALE FOR IMMUNOTHERAPY IN mCRC}

\section{Immune Checkpoint Molecules}

Immune checkpoints were originally essential molecules for preventing autoimmunity, but their existence has become a mechanism by which tumors escape the surveillance of the immune system (7). Common immune checkpoint molecules include programmed death cell protein 1 (PD-1), programmed death-ligand 1(PD-L1) and cytotoxic T-lymphocyte-associated protein 4 (CTLA-4). PD-1 is a transmembrane protein, mainly expressed on the surface of a variety of immune cells (e.g., T cells, B cells, dendritic cells, and NK cells) and the corresponding receptor PD-L1 expressed on the surface of tumor cells. The PD-1 signaling pathway can negatively regulate the human immune system, thereby inhibiting the Th1 cytotoxic activity and damaging the host, as did PD-L1 and CTLA-4 (8). Specifically, when PD1 interacts with PD-L1, downstream signaling pathways are induced to directly inhibit tumor cell apoptosis and stimulate the conversion of effector $\mathrm{T}$ cells to regulatory $\mathrm{T}$ cells (Tregs). In a similar manner, CTLA-4 on the surface of T cells can preferentially bind to the receptors (B7-1; B7-2) on the surface of antigen-presenting cells (APC) due to their higher affinity, so that the activity of $\mathrm{T}$ cells is reduced, their proliferation is inhibited, and their anti-tumor effect is weakened (9) (Figure 1). These molecules have been found to be overexpressed in solid tumors and in their microenvironment. Wei

\footnotetext{
Abbreviations: mCRC, metastatic colorectal cancer; MSI/dMMR, microsatellite instability/mismatch-repair-deficiency; MSS/pMMR, microsatellite stability/ mismatch-repair-proficiency; ICIs, immune checkpoint inhibitors; ACI, adoptive cellular immunotherapy; CT, chemotherapy; RFA, radiofrequency ablation; RT, radiotherapy; CTLA-4, cytotoxic T-lymphocyte-associated protein 4; PD-1, programmed cell death 1; PD-L1, PD-1 ligand; Treg, regulatory T cell; DC, dendritic cell; NK cell, natural killer cell; APC, antigen-presenting cell; TLR, toll-like receptor; OS, overall survival; PFS, progression-free survival; ORR, objective response rate; irORR, immune-related objective response rate; $\mathrm{DCR}$, disease control rate; BSC, best supportive care; 5-FU, 5-flourouracil; 5-FU/LV, 5 flourouracil, leucovorin; FOLFOX, 5-flourouracil, leucovorin, oxaliplatin; FOLFIRI, 5-flourouracil, leucovorin, irinotecan; FOLFOXIRI, 5-flourouracil, leucovorin, oxaliplatin, irinotecan.
}

et al. found that the levels of PD-L1 in liver metastases were higher compared with primary tumors (10). The immune escape of the tumors was reversed by immune checkpoint inhibitors, novel drugs developed to block these negative feedback pathways by binding to PD-1 (nivolumab, pembrolizumab), PD-L1 (atezolizumab), CTLA4 (ipilimumab). Many existing clinical trials have demonstrated encouraging results in a variety of solid tumors, directly leading to FDA approval of some of these drugs for clinical use (11).

\section{mCRC With MSI/dMMR or MSS/pMMR}

With the recognition of the potential of immunotherapy to improve some patients with advanced solid tumors, it is apparent that we need new biomarkers that can distinguish between tumors that respond to immunotherapy and those that do not. Some studies showed that there is a strong connection between mutation prevalence and immunotherapy response (12). After that, CRC can be divided into two discrete groups according to the MMR mutation status: MSI/dMMR tumors mainly with high overall mutation burden and MSS/ pMMR tumors mostly with relatively much lower mutation burden (13). Sad to say, only about $2-4 \%$ of mCRC was diagnosed as MSI/dMMR (14). DNA mismatch repair (MMR) is to ensure the integrity and stability of genetic material by correcting mismatched bases during DNA replication. When the mismatch repair system is defective in the main MMR proteins MLH1, MSH2, MSH6, and PMS2 or microsatellites, multiple mutations accumulate, eventually leading to the development of tumors called mismatch-repair deficiency/microsatellite instability (MSI/dMMR) tumors (15). Immunohistochemistry and PCR are commonly used to diagnose patients with MSI/ dMMR or MSS/pMMR. One of the mechanism by which dMMR tumors are sensitive to immunotherapy is the production of multiple neoantigens induced by genomic mutations (16). More importantly, immune cells (CD8+ infiltrating lymphocytes; CD4+ TILS; macrophages; NK cells) are abundant in MSI-H/dMMR tumors and cell surface inhibitory checkpoint molecules of lymphocytes and tumor cells (PD-1, PD-L1, respectively) are increased correspondingly $(17,18)$ (Figure 2). This also means that the corresponding MSS tumor is less likely to respond to immunotherapy, which is showed in multiple studies (19). This is a barrier to immunotherapy that needs to be addressed.

\section{IMMUNE CHECKPOINT INHIBITORS THERAPY}

Since mCRC patients' response to ICIs can vary significantly depending on MMR status, we will focus on mCRC patients with MSI/dMMR or MSS/pMMR here (Table 1).

\section{MSI/dMMR MCRC}

The efficacy of ICIs was studied in mCRC patients before the patients were stratified with MSS status. In a phase I study of nivolumab (anti-PD-1) in the 39 patients with treatment-refractory solid tumors, only one mCRC patient $(7 \%, 1 / 14)$ achieved a lasting complete response for 6 months (27). Similarly, in another phase I study of nivolumab $(n=296)$, objective responses were observed 


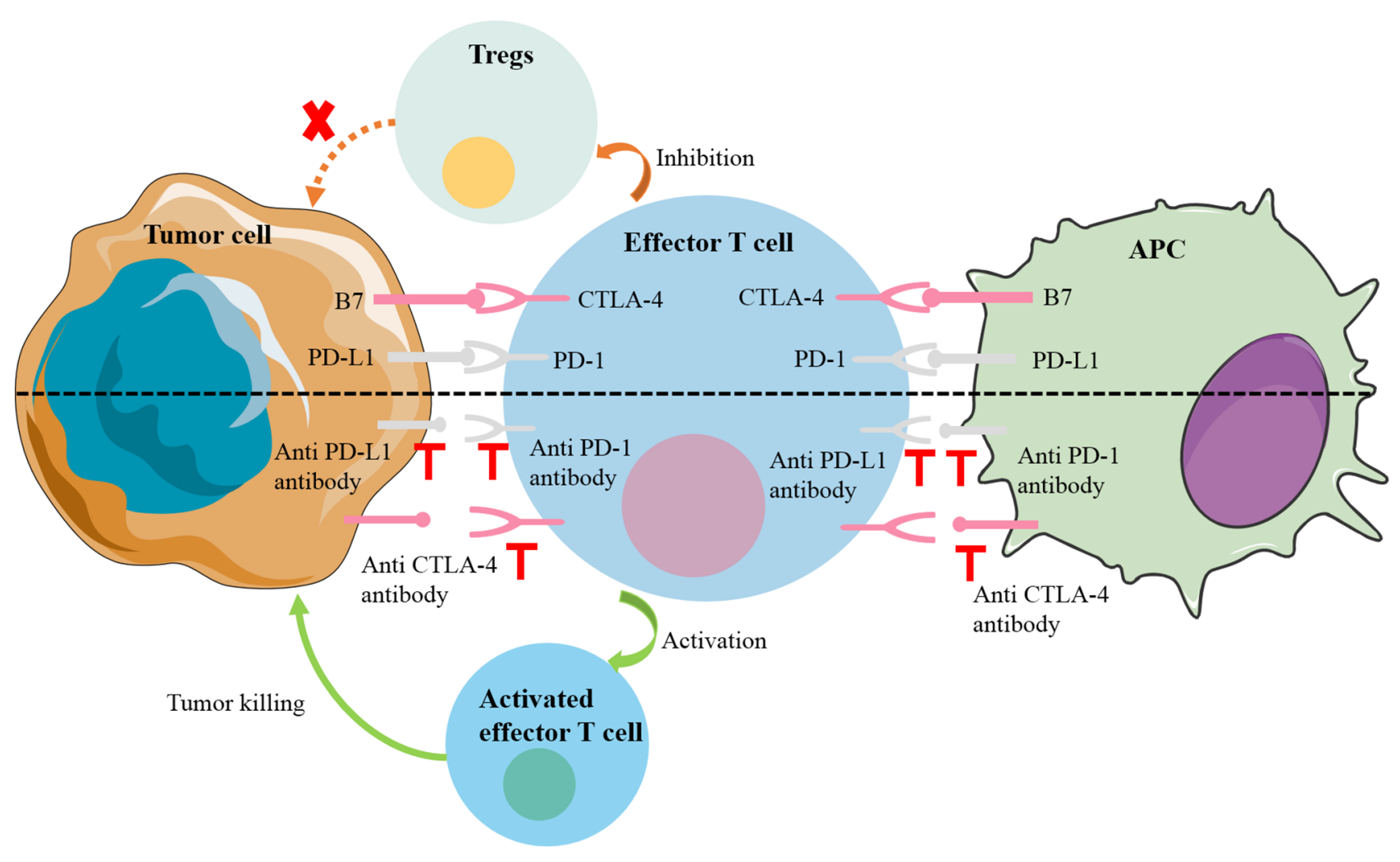

FIGURE 1 | Mechanisms of common immune checkpoint inhibitors. PD1 on the surface of effector T cells interacts with PD-L1 on the surface of tumor cells, downstream signaling pathways are induced to directly inhibit tumor cell apoptosis and stimulate the conversion of effector $T$ cells to Tregs. In a similar manner, CTLA-4 on the surface of T cells can preferentially bind to the receptors (B7-1; B7-2) on the surface of APC to inhibit the activity and proliferation of T cells. APC, antigen-presenting cell; CTLA-4, cytotoxic T-lymphocyte-associated protein 4; PD-1, programmed cell death 1; PD-L1, PD-1 ligand; Treg, regulatory T cell.

only in patients with non-small cell lung cancer, melanoma, or renal cell carcinoma, and not in the mCRC population (0 of 19,0\%) (20). A phase II study of tremelimumab (CTLA4) in the 47 patients with refractory metastatic colorectal cancer also failed, only one patient (2\%) achieved partial response (28). These studies suggested that single-agent immune checkpoint therapy is not effective in unselected mCRC. This has led to a shift to research into population-specific immunotherapies in mCRC, such as MSI-H/ DMMR mCRC and MSS/PMMR mCRC. In a population-based cohort of 798 mCRC patients, Aasebø et al. reported that the proportion with MSI-H among mCRC patients is nearly twice as high as most previous reports of $\operatorname{mCRC}(4,3.5,4.2,5 \%)(21,22,32$, 33), with 40/583 (7\%) tumor samples of MSI-H (23). Wang et al. evaluated the status of MMR and MSI in 40 pairs of situ tumors and liver metastases by immunohistochemistry (IHC) and Polymerase Chain Reaction (PCR) respectively. inconsistent MMR and MSI status were observed in ' $15 \%$ patients (six of 40 patients). There was no significant difference between primary and metastatic tumors in the expression status of MMR $(\mathrm{P}=0.1405)$ (24). Although the proportion of patients with $\mathrm{dMMR}$ in metastatic colorectal cancer is not high, the poor prognosis in mCRC patients makes any treatment that can improve survival significant.

Le et al. conducted a phase 2 study that evaluated the clinical efficacy of pembrolizumab(anti-PD1) in the 32 patients with advanced metastatic cancer with and without dMMR. For dMMR mCRC patients, 40\% (four of 10 patients; 95\% CI, 12 to 74) achieved immune-related objective response and $78 \%$ (seven of nine patients; 95\% CI, 40 to 97) survive without progression for 20 weeks, compared with $0 \%$ (0 of 18 patients; $95 \%$ CI, 0 to 20 ) and $11 \%$ (two of 18 patients; $95 \%$ CI, 1 to 35 ) in pMMR CRC. A disease control rate (DCR) of $>12$ weeks was achieved in 90\% dMMR mCRC and 11\% pMMR mCRC (8). The efficacy of another anti-PD1 drug nivolumab on MSI/AdMMR mCRC was confirmed in a phase 2 study (CheckMate 142). At a median follow-up of 12.0 months, investigator-assessed objective response (OR) was $31.1 \%$ (23 of 74 patients, 95\% CI, 20.8-42.9) and DCR for 12 weeks or longer was $69 \%$ (51 of 74 patients; $95 \%$ CI, 57 to $79 \%)$. Two patients $(2.7 \%)$ had complete responses (CRs) and 22 patients (29.7\%) had partial responses (PRs) (25). And on this basis the study further evaluated the role of nivolumab plus ipilimumab(anti-CTLA-4) on MSI/dMMR mCRC patients. At median follow-up of 13.4 months, 55\% patients achieved investigator-assessed objective response, and DCR for $\geq 12$ weeks was $80 \%$. Progression-free survival (PFS) rate and overall survival (OS) rate at one year was 71 and $85 \%$, respectively. Surprisingly, in 16 patients (13\%) who did not complete the treatment cycle due to immune-mediated toxicity, $63 \%$ of these achieved the OR, comparable to the total 


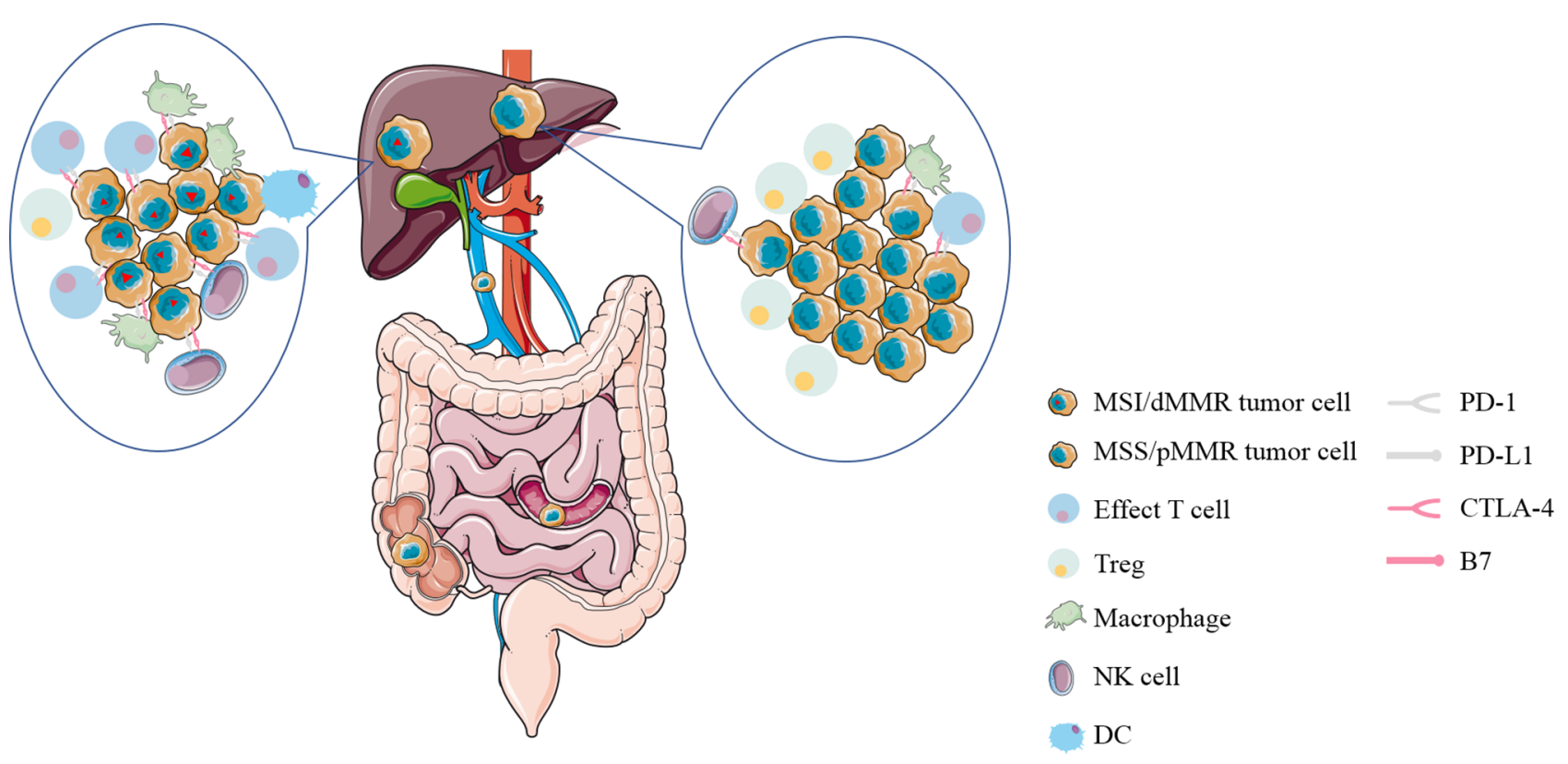

FIGURE 2 | The immune microenvironment of liver metastases from colorectal cancer with MSI/dMMR or MSS/pMMR. Immune cells (CD8+ infiltrating lymphocytes; CD4+ TILS; macrophages; NK cells) are abundant in MSI-H/dMMR tumors and inhibitory checkpoint molecules on the surface of lymphocytes and tumor cells (PD1, PD-L1, respectively) are increased correspondingly. MSI/dMMR, microsatellite instability/mismatch-repair-deficiency; MSS/pMMR, microsatellite stability/mismatchrepair-proficiency; CTLA-4, cytotoxic T-lymphocyte-associated protein 4; PD-1, programmed cell death 1; PD-L1, PD-1 ligand; Treg, regulatory T cell; DC, dendritic cell; NK cell, natural killer cell.

population (34). A couple of studies above led to FDA approval of pembrolizumab and nivolumab for $\mathrm{dMMR}$ CRC previously treated by conventional chemotherapy.

Recently, a phase 3 study comparing the clinical effect of PD-1 blockade and chemotherapy as first-line treatment in MSI-H-DMMR $\mathrm{mCRC}$ was reported. Some 307 previously untreated mCRC patients with MSI-H-dMMR were randomly assigned to two groups at a ratio of $1: 1$, and received $200 \mathrm{mg}$ of pembrolizumab every 3 weeks or chemotherapy every 2 weeks, respectively. At a median follow-up of 32.4 months, median PFS was 16.5 months for the pembrolizumab group, compared with 8.2 months for the chemotherapy group, respectively $(\mathrm{P}=0.0002)$. About $43.8 \%$ patients in the pembrolizumab group had OR and $33.1 \%$ in the chemotherapy group. In addition, $22 \%$ of patients in the pembrolizumab group experienced treatment-related adverse events of grade 3 or higher, while $66 \%$ in the chemotherapy group (including one death). As a firstline treatment for MSI-H-DMMR metastatic colorectal cancer, pembrolizumab can remarkably improve PFS and reduced treatment-related adverse events, compared with chemotherapy (35). This further suggests that for MSI-H-DMMR metastatic colorectal cancer, chemotherapy is not recommended and immunotherapy should be accepted. But the remarkable thing is that $153(50 \%)$ had synchronous liver metastases, and 77 (25\%) had BRAFV600E mutant tumors. This means that more accurate stratification is needed to further study the efficacy of immunotherapy and chemotherapy on MSI-H-DMMR mCRC patients.

Additionally, the anti-PD-L1 therapy of patients has also been increasingly studied. In a phase II study of Avelumab in the 21 patients with dMMR/MSI-H mCRC, complete response rate (CRR) and partial response (PRR) were both $14.3 \%$ (three patients), with ORR and DCR of 28.6 and 90.5\%, respectively. At a median follow-up of 16.3 months, median PFS was 8.1 months (95\% CI, 1.1 to 15.1 months) (36). Chen et al. conducted a phase 2 study to assess whether combination therapy with antiPD-L1 and anti-CTLA-4 is effective in patients with intractable mCRC. With a median follow-up of 15.2 months, the median OS was 6.6 months for durvalumab and tremelimumab, compared with 4.1 months for best supportive care (BSC) alone $(\mathrm{P}=.07)$. However, PFS was 1.8 and 1.9 months respectively. There was no CR. It is worth noting that durvalumab plus tremelimumab significantly improved OS in MSS patients (HR, 0.66; 90\% CI, $0.49-0.89 ; \mathrm{P}=.02$ ). This underlines the possibility of combining immunotherapy in unselected advanced mCRC (37).

What is the effect of immunotherapy as neoadjuvant therapy in perioperative period? In a retrospective study of eight patients with advanced MSI-H CRC, pathologic complete response was observed in five of the seven resected patients, and clinical complete response was observed in an unoperated patient (26). In another retrospective analysis of 121 advanced dMMR mCRC patients treated with ICIs, 13 patients achieved pathologic complete response as is shown in the resected specimens. Preoperative imaging in 12 of those patients, however, still showed residual tumor. The result indicates that patients with residual radiographic tumors may not need surgery based on anti-PD1 response (38). In general, the possibilities of ICIs for mCRC continue to expand. 
TABLE 1 | Summary of Immune Checkpoint Inhibitors Therapies for MCRC.

\begin{tabular}{|c|c|c|c|c|c|c|}
\hline Study & Phase & Agent & Population & MSI status & Endpoint & Reference \\
\hline NCT00730639 & 1 & anti-PD-1 (MDX-1106) & $\begin{array}{l}296 \text { advanced } \\
\text { solid tumors, } \\
\text { including19 } \\
\text { CRC }\end{array}$ & - & - & (20) \\
\hline NCT01876511 & 2 & anti-PD-1 (pembrolizumab) & $\begin{array}{l}41 \text { advanced } \\
\text { tumors, } \\
\text { including } 32 \\
\text { mCRC }\end{array}$ & $\begin{array}{l}\text { dMMR }(\mathrm{n}= \\
\text { 11) } \mathrm{pMMR} \\
(\mathrm{n}=21)\end{array}$ & $\begin{array}{l}\text { The primary endpoints: } \\
\text { immune-related objective response rate and the } \\
20 \text {-week immune-related progression-free } \\
\text { survival rate }\end{array}$ & (8) \\
\hline NCT02060188 & 2 & anti-PD-1 (nivolumab) & $\begin{array}{l}74 \text { recurrent or } \\
\text { metastatic } \mathrm{CRC}\end{array}$ & $\mathrm{dMMR}$ & $\begin{array}{l}\text { The primary endpoints: } \\
\text { investigator-assessed ORR }\end{array}$ & $(21)$ \\
\hline NCT02060188 & 2 & $\begin{array}{l}\text { anti-PD-1 (nivolumab) + } \\
\text { anti-CTLA4 (ipilimumab) }\end{array}$ & $\begin{array}{l}119 \text { recurrent } \\
\text { or metastatic } \\
\text { CRC }\end{array}$ & $\mathrm{dMMR}$ & $\begin{array}{l}\text { The primary endpoints: } \\
\text { investigator-assessed ORR; } \\
\text { The secondary endpoints: } \\
\text { ORR per blinded independent central review } \\
\text { (BICR) and DCR }\end{array}$ & (22) \\
\hline NCT02563002 & 3 & $\begin{array}{l}\text { anti-PD-1 (pembrolizumab) } \\
\text { or chemotherapy (5-fluorouracil-based } \\
\text { therapy with or without bevacizumab or } \\
\text { cetuximab) }\end{array}$ & $307 \mathrm{mCRC}$ & dMMR & $\begin{array}{l}\text { The primary endpoints: } \\
\text { PFS and OS; } \\
\text { The secondary endpoints: } \\
\text { OS and safety }\end{array}$ & (23) \\
\hline NCT03150706 & 2 & anti-PD-L1 (avelumab) & $33 \mathrm{mCRC}$ & $\begin{array}{l}\text { dMMR } \\
(\mathrm{n}=30)\end{array}$ & $\begin{array}{l}\text { The primary endpoint: } \\
\text { ORR }\end{array}$ & $(24)$ \\
\hline NCT02870920 & 2 & $\begin{array}{l}\text { Anti-PD- L1 (durvalumab) + anti-CTLA4 } \\
\text { (ipilimumab) + best supportive care (BSC); } \\
\text { or BSC alone }\end{array}$ & $180 \mathrm{mCRC}$ & $\mathrm{dMMR}$ & $\begin{array}{l}\text { The primary endpoint: } \\
\text { OS }\end{array}$ & $(25)$ \\
\hline NCT03350126 & 2 & $\begin{array}{l}\text { Anti-PD-1 (nivolumab) plus anti-CTLA4 } \\
\text { (ipilimumab) }\end{array}$ & $57 \mathrm{mCRC}$ & dMMR & $\begin{array}{l}\text { the frequency of pseudoprogressions (DCR by } \\
\text { RECIST and iRECIST at } 12 \\
\text { weeks) }\end{array}$ & (26) \\
\hline- & 1 & Anti-PD-1 (MDX-1106) & $\begin{array}{l}14 \text { advanced } \\
\mathrm{mCRC}\end{array}$ & - & $\begin{array}{l}\text { The primary objectives: } \\
\text { safety; tolerability; maximum-tolerated dose; } \\
\text { pharmacokinetics. } \\
\text { The secondary objectives: assessing antitumor } \\
\text { activity, pharmacodynamics, immunologic end } \\
\text { point }\end{array}$ & $(27)$ \\
\hline- & 2 & anti-CTLA4 (tremelimumab) & $\begin{array}{l}47 \text { refractory or } \\
\text { metastatic CRC }\end{array}$ & - & $\begin{array}{l}\text { The primary endpoints: } \\
\text { objective response; } \\
\text { The secondary endpoints : } \\
\text { safety, duration of } \\
\text { response, PFS, and OS }\end{array}$ & (28) \\
\hline NCT02788279 & 3 & $\begin{array}{l}\text { atezolizumab + cobimetinib or } \\
\text { atezolizumab monotherapy versus } \\
\text { regorafenib }\end{array}$ & $\begin{array}{l}383 \text { advanced } \\
\text { or metastatic } \\
\text { CRC }\end{array}$ & MSS & $\begin{array}{l}\text { The primary endpoints: } \\
\text { OS; } \\
\text { The secondary endpoints: investigator-assessed } \\
\text { OR, duration of response, and PFS }\end{array}$ & (19) \\
\hline NCT03912857 & 2 & anti-PD-1(SHR-1210) + apatinib & $10 \mathrm{mCRC}$ & MSS & $\begin{array}{l}\text { The primary endpoints: } \\
\text { ORR; } \\
\text { The secondary endpoints: PFS, OS, DCR and } \\
\text { safety. }\end{array}$ & (29) \\
\hline NCT02851004 & 2 & $\begin{array}{l}\text { anti-PD-1 (pembrolizumab) + } \\
\text { STAT3 inhibitor (napabucasin) }\end{array}$ & $50 \mathrm{mCRC}$ & MSS $(n=40)$ & $\begin{array}{l}\text { The primary endpoints: } \\
\text { irORR }\end{array}$ & $(30)$ \\
\hline NCT03406871 & $1 b$ & anti-PD-1 (nivolumab) + regorafenib & $\begin{array}{l}50 \text { patients, } \\
\text { including } 25 \\
\mathrm{mCRC}\end{array}$ & $\operatorname{MSS}(n=24)$ & $\begin{array}{l}\text { Secondary objectives: } \\
\text { assessing incidences of adverse events, ORR, } \\
\text { DCR, PFS, and OS. }\end{array}$ & (31) \\
\hline
\end{tabular}

OS, overall survival; PFS, progression-free survival; ORR, objective response rate; irORR, immune-related objective response rate; DCR, disease control rate; BSC, best supportive care; PD-1, programmed cell death 1; PD-L1, programmed cell death ligand-1; CTLA-4, cytotoxic T-lymphocyte-associated protein 4; 5-FU, 5-flourouracil; FOLFOX, 5-flourouracil, leucovorin, oxaliplatin; FOLFIRI, 5-flourouracil, leucovorin, irinotecan; mCRC, metastatic colorectal cancer; MSI, microsatellite instability-(high); MSS, microsatellite stability.

Although ICIs has made significant progress in dMMR mCRC, the objective response rates shown in various studies were still unsatisfactory. This may be due to the following reasons. The first reason is misdiagnosis. In a post hoc analysis of 38 patients with mCRC diagnosed as MSI/dMMR, five individuals $(13 \%)$ were resistant to immune checkpoint inhibitors. After reassessment of the status, three of these patients (60\%) were confirmed as MSS/pMMR. Misdiagnosis of their MSI/dMMR status is the main cause of the resistance to ICIs in MCRC shown as MSI/dMMR. Therefore, Cohen et al. advocated that immunohistochemistry and polymerase chain reaction should be combined routinely to detect of MSI/MMR status prior to ICIs. But this increases the cost of the tests, which may be bad for future adoption (39). The second reason is tumor 
heterogeneity. Although MSI is considered to be an early event of $\mathrm{CRC}$, there is the possibility of heterogeneity in MSI/dMMR tumors. In a case report, a mCRC patient was found to possess immunohistochemical and molecular heterogeneity in MSI/ dMMR status in the primary tumor. Significantly, treatment with nivolumab plus ipilimumab showed clear clinical benefit for the patients, with a deep and lasting response. This conclusion needs to be further confirmed by large sample studies (40). The presence of pseudoprogression (PSPD) is also a possible cause. After treatment, the phenomenon of enlargement of the original lesion or the appearance of new lesion, which is similar to the recurrence of tumor, called pseudoprogression. Pseudoprogression could be misjudged as unresponsive status, resulting in the difficulties with the following treatment choices. Colle et al. retrospectively analysis the data of 123 patients with MSI/dMMR mCRC treated with ICIs. About $10 \%$ of the population $(12 / 123)$ experienced PSPD. The median time to PSPD was 5.7 weeks $(95 \%$ CI, 4.1-11.4), however, after 3 months, no one experienced PSPD. Some nine of 61 patients (14.8\%) had PSPD in the anti-PD1 alone group, compared with three of 62 patients $(4.8 \%)$ in the anti-PD1 plus anti-CTLA-4 group. These results suggest that iRECIST criteria should be questioned after 3 months of immunotherapy (41). In a phase II study of 57 patients with MSI/dMMR mCRC treated with nivolumab and ipilimumab, only 3.5\% (2/57) patients experienced PSPD. This result is consistent with the previous study (42). Parseghian et al. found that PSPD was not seen in 59 MSS mCRC treated with immunotherapy, which may be related to its poor efficacy (29). There are many other mechanisms of drug resistance in tumors. It is well known that CD8+ cytotoxic T lymphocytes (CTLs) are the main immune cells that kill target tumor cells in cancer immune surveillance. In terms of mechanism, Fas-FasL apoptosis pathway plays an important part (43). Fas is a cell surface receptor of the tumor necrosis factor receptor superfamily, which is expressed multiple kinds of cells including tumor cells. FasL is also a member of the tumor necrosis factor superfamily, but it is selectively expressed in activated $\mathrm{T}$ cells and NK cells. The binding of Fas and its ligand FasL induces the trimerization of Fas receptors, and then forms the death-inducing signal complex (DISC) in the cytoplasmic region of Fas receptors, and cleaves procaspase- 8 at DISC, resulting in Fas-mediated cells apoptosis (44). In vivo and in vitro, Xiao et al. found that Fas expression was decreased in a subset of CD133+CD24lo colon cancer cells, leading to immune evade (31). In addition, the neoantigen is likely to form a complex with human leukocyte antigen class I (HLA class I) on the surface of tumor cells and presented by antigen-presenting cells in dMMR tumors. However, it has been reported that HLA class I expression defects occur in most dMMR CRC, which will prevent the antigen presentation of these tumors $(30,45)$. Likewise, Ijsselsteijn et al. determined that majority (73-78\%) of dMMR cases in two independent cohorts of CRC had loss of HLA class I expression, which may cause immune escape (46).

\section{MSS/pMMR mCRC}

Unfortunately, MSS/pMMR mCRC patients in the ICIs trials failed to gain any clinically significant response or survival benefit from either monotherapy or dual therapy. Eng et al. reported a phase III study of 363 patients with MSS mCRC treated with atezolizumab plus cobimetinib or atezolizumab monotherapy or regorafenib in the third-line setting.After a median follow-up of 7.3 months, Median overall survival was 8.87 months (95\% CI 7.00-10.61) in the atezolizumab plus cobimetinib group, 7.10 months (6.05-10.05) in the atezolizumab group, and 8.51 months (6.41-10.71) in the regorafenib group. None of the three groups achieved complete response. Partial response rate was $3 \%$ (five of 183) in the combination group, 2\% (two of 90) in the atezolizumab group, $2 \%$ (two of 90) in the regorafenib group. In general, there is no significant difference across all three groups in OS, PFS, OR, and duration of response (19). In a phase II study of 10 patients with MSS mCRC treated with SHR-1210 (anti-PD-1) plus apatinib, no one $(0 \%)$ achieved OR and two (22.2\%) patients achieved disease control. The median PFS and the median OS was 1.83 months (95\% CI, 1.80-1.86 months) and 7.80 months (95\% CI, 0-17.07). In conclusion, MSS mCRC failed to benefit from SHR-1210 combined with apatinib (47). In a retrospective study of 23 MSS or pMMR mCRC treated with regorafenib plus antiPD-1 antibody, ORR was $0 \%$ and DCR was $78.3 \%$ (18/23), with the median PFS of 3.1 months (95\% CI, 2.32-3.89). The results are consistent with clinical trials above (48). In another retrospective study, Wang et al. found that MSS CRC patients with no history of liver metastasis are more likely to benefit from this combination regorafenib plus antiPD-1 antibody (49).

However, the recent results of a phase $\mathrm{Ib}$ trial suggest the encouraging antitumor activity of regorafenib plus nivolumab in MSS mCRC, with ORR of 36\% (9/25) and median PFS of 7.9 months in mCRC (50). In a recent phase II clinical trial, mCRC patients with MSS seemed to benefit from napabucasin (STAT3 inhibitor) plus pembrolizumab, with irORR of $10.0 \%$ (four of 40 patients; 95\% CI, 2.8-23.7) (51). These conflicting results indicate that the combination of molecular targeted therapy with immunotherapy remains controversial for MSS patients and there is no conclusive evidence to validate its efficacy. With clinical trials of multiple molecular targeted therapies under way, this remains a promising therapeutic strategy for MSS patients. Before the era of immunotherapy, the efficacy of chemotherapy alone in CRC patients with MSS is also limited. In an ACCENT pooled analysis of seven studies, survival time after recurrence in stage III CRC patients with MSS/pMMR treated with adjuvant chemotherapy was shorter compared with those MSI/dMMR patients (52). Martin-Romano et al. reported that pts with refractory MSS mCRC might benefit from chemotherapy after ICI. In the retrospective study of 29 pts with mCRC received chemotherapy after ICI failure [MSS tumors, 27 pts (86\%)], four patients (19\%) achieved partial response and 9 pts (43\%) achieved stable disease, with disease control rate of $62 \%$. The median PFS and OS were 3.8 months $(95 \% \mathrm{CI}=1.5-5.4)$ and 8.0 months $(95 \%$ CI $=4.2-14.0)$, respectively. Since single chemotherapy or single immunotherapy is not effective, this also suggests the potential efficacy of chemotherapy combined with immunotherapy in MSS patients (53).

\section{Biomarkers of Immune Response}

Microsatellite instability (MSI) is recognized as a biomarker to predict the response to ICIs in solid tumors. The KEYNOTE-016 
trial underlined the utility of MSI-H:dMMR as a predictive biomarker to antiPD-1 therapy (pembrolizumab) in mCRC (8). High DCR and beneficial PFS were observed in in mCRC patients with MSI-H treated by PD-1 inhibitors; however, less than half of the patients had clinical response, suggesting that patients needed additional predictive biomarkers. MSI-H tumors tend to have high tumor mutational burden (TMB), and studies have demonstrated that TMB is commonly increased in MSI-H mCRC, but still unclear (54). In mCRC patients treated with durvalumab and tremelimumab, OS is the greatest in MSS Patients with more plasma TMB of 28 variants per megabase or more (HR, 0.34; 90\% CI, 0.18-0.63; P = .004) (37). Schrock et al. analyzed $\mathrm{TMB}$ in 22 patients treated with $\mathrm{PD}-1 / \mathrm{L} 1$ inhibitors, TMB was strongly associated with objective response (OR; $\mathrm{P}<0.001)$ and $\mathrm{PFS}$, by univariate $(\mathrm{P}<0.001)$ and multivariate analysis $(\mathrm{P}<0.01)$. At a median follow up of 18 months, patients with high TMB has not reached the median PFS while patients with low TMB had median PFS of only 2 months. In MSI-H mCRC, TMB appears to be a crucial independent biomarker, which can stratify patients who may respond to ICIs (55). By analyzing CRC tissue sections, 164 of 5,702 (2.9\%) MSS cases were assessed as TMB-high. It means that more people may benefit from ICI When TMB was used as a prognostic marker (56). However, based on the clinical response data collected from six patients with metastatic MSIH/DMMR GI cancers treated by ICIS, Hirsch et al. found that TMB wasn't associated with extent and duration of response (57). By comparing the expression of 44 selected immune-related genes in the primary colon tumor between responders $(n=13)$ and nonresponders $(n=6)$ after anti-PD-1 therapy, Llosa et al. concluded that preexisting antitumor immune response has little predictive value for immunoreactive pMMR CRC (58). A growing body of evidence suggests that infiltrating lymphocytes are inextricably associated with TMB, infiltrating lymphocytes is also an important prognostic marker for CRC patients after ICIs. High infiltrating lymphocytes densities (CD3, CD8, FoxP3, and $\mathrm{CD} 45 \mathrm{RO}$ ) had significant correlation with improved overall survival for primary colorectal cancer (all p <0.001). Moreover, the densities of CD8 cells predicted the good tumor regression grade well in locally advanced rectal cancer after chemoradiotherapy (59). In a study, Loupakis et al. collected data from 85 patients with MSI-H mCRC treated with ICIs. RR in patients with high number of TILs (TILs-H) and those with low number of TILs was 70.6 and $42.9 \%$, respectively (odds ratio = $3.20, \mathrm{p}=.0291)$. Patients with TILs- $\mathrm{H}$ had better survival outcomes than those with TILs-L (PFS: not reached vs 27.8 months, HR $=0.42, \mathrm{p}=.0278$; OS: $\mathrm{HR}=0.41, \mathrm{p}=.0463)(60)$.

In addition to these now routinely studied, some new biomarkers are increasingly being studied. The levels of B7-H3, $\mathrm{B} 7-\mathrm{H} 4$, and PD-L1 protein in tissues from 805 primary tumors and matched metastases were evaluated by microarrays. Detectable rate of B7-H3, B7-H4 and PD-L were 50.9, 29.1 and $29.2 \%$, and elevated B7-H3 expression had an association with advanced overall stage. B7-H3 overexpression in primary tumors predicted poor DFS, while B7-H4 and PD-L1 had no significant relationships with survival. Overall, B7-H3 had a higher expression rate than $\mathrm{B} 7-\mathrm{H} 4$ and $\mathrm{PD}-\mathrm{L} 1$, and was significantly associated with poor prognosis (61). Lu et al. found mCRC patients with early decrease in serum interleukin 1 receptor antagonist had longer PFS (not reached vs 2.1 months; HR = 0.06; 95\% CI, 0.01 to 0.38 ; $\mathrm{P}<.001$ ). Compared with MSI status or PD-L1 expression, an early decrease in serum interleukin 1 receptor antagonist can better determine who will respond to ICIs in patients with metastatic CRC (62). A case was reported that a mCRC patient who carried the rare 9p24.1 CNG achieved a lasting partial response after immunotherapy, which may support the use of ICIs in solid tumors carrying the rare 9p24.1 CNG (63). The evaluation of TMB and TILs should be incorporated into future trials of ICIs in mCRC to confirm our results and to explore methods and threshold issues for routine clinical use.

\section{ADOPTIVE CELLULAR IMMUNOTHERAPY}

Generally, autologous $\mathrm{T}$ cells were targeted to tumor specific antigens by gene editing, then were injected back into the patient to stimulate the host antitumor immune response. As significant efficacy was reported in a large amount of hematologic malignancies and solid tumors, adoptive T-cell therapy is recently another novel immunotherapy option for mCRC patients. In gastrointestinal tumors, cancer embryonic antigen (CEA) is a sensitive tumor biomarker, which can be detected in CRC tissues and serum with increased levels. In one of the earliest clinical trials, three refractory mCRC patients were administered autologous $\mathrm{T}$ lymphocytes genetically engineered to express a murine $\mathrm{T}$ cell receptor (TCR) against human carcinoembryonic antigen (CEA). Levels of CEA in serum were profoundly decreased in all patients (74-99\%), and objective shrinkage of liver and lung metastatic lesions was observed in one patient, although a severe transient inflammatory colitis was observed in all three patients (64). In a phase I study of CEA CAR-T cell in 10 CEA+ mCRC patients, seven progressive patients had stable disease after CAR-T therapy. Among them, two patients maintained more than 30 weeks, and two patients showed tumor regression. In conclusion, most treated patients achieved some efficacy (65). Here Hege et al. report results of trials of CAR-T cells targeting tumorassociated glycoprotein (TAG)-72 (CART72 cells) in the treatment of metastatic colorectal cancer. CART72 cells in blood last for a short time ( $\leq 14$ weeks), and CART72 cells in tumor tissues can be detected in tumor biopsy from one of three patients. CART72 cells had limited efficacy in mCRC, suggesting that incorporation of co-stimulatory domains in the CAR design was needed (66). The study showed that postoperative CRC patients may benefit from adjuvant sentinel lymph nodes lymphocyte (SLN-T) immunotherapy. 1-year survival rate in SLN-T lymphocyte group was $55.6 \%$, compared with $17.5 \%$ in the control group $(\mathrm{p}=0.02)$. The median OS of the SLN-T lymphocyte was 28 months, compared with 14 months of the control group (67). In addition, specific T cells targeting other neoantigens detected in tumor tissue can also be used for treatment. In a case report, objective regression of all seven lung metastases was observed after the transfusion of tumor- 
infiltrating lymphocytes specifically targeted KRAS G12D, which was identified in tumor-infiltrating lymphocytes obtained from a patient with metastatic colorectal cancer (68). In another case report, tumor-infiltrating lymphocytes with HLA-A ${ }^{*} 0201$ restricted recognition of mutated p53 p.R175H were identified, which can mediated recognition of multiple epithelial cancers that expresses both HLA-A ${ }^{\star} 0201$ and the p53 p.R175H mutation (69). CD4+ and CD8+ memory $\mathrm{T}$ cells targeting the mutated KRASG12D and KRASG12V variants respectively in the peripheral blood of cancer patients were conformed and isolated, suggesting that we can detect memory $\mathrm{T}$ cells targeting distinct or common somatic mutations in the peripheral blood of epithelial cancer patients and can hopefully use them to develop efficient individualized $\mathrm{T}$ cell-based cancer immunotherapy among a variety of patients (70).

Because NK cells can induce antitumor activity, independent of antigen and major histocompatibility complex (MHC), increasing clinical trials are testing the efficacy of adoptive cancer therapy with NK cells. NK cells treatment effectively extend the lives of leukemia patients. Due to good therapeutic effect and safety, NK cell therapy is considered to be superior to adoptive therapy of autologous $\mathrm{T}$ cells, however, many clinical trials of NK cells in solid tumors failed to achieve end points. Veluchamy et al. confirmed the antitumor efficacy in vivo and in vitro where umbilical cord blood stem cellderived NK cells (UCB-NK) showed enhanced antitumor cytotoxicity against colon cancer cells independent of EGFR and RAS status (71). Xiao et al. used CAR-NK cells fusing the extracellular domain of the natural killer (NK) cell receptor NKG2D to DAP12 to treat three mCRC patients. Ascites and number of tumor cells in ascites samples were decreased in the first two patients after treatment with intraperitoneal injection of the CAR-NK cells. The third patient with liver metastatic experienced tumor regression in the liver region after treatment with intraperitoneal infusion of the CAR-NK cells following percutaneous injection (72).

In addition, the synergistic anti-tumor immunity of $\mathrm{T}$ cells and NK cells can also be achieved by targeting NKG2D for T cells. In an animal experiment, tumor burden was significantly reduced in established peritoneal colorectal xenografts after treatment with CAR-T cells specific for NKG2D ligands (73).

\section{VACCINE THERAPY}

Colorectal cancer overexpressed some common tumor associated antigens, which can serve as a target for vaccine in immunotherapy. Multiple types of vaccines studied in mCRC include autologous, peptide, and dendritic cell vaccines (Table 2). A phase I/II trial of p53 synthetic long peptide (p53-SLP) vaccine was performed in ten mCRC patients. p53specific $\mathrm{T}$-cell reactivity ( $\geq 6$ months) was observed in $67 \%$ patients (six of nine), however, polarized p53-specific CD4 $+\mathrm{T}$ cells accounted for only a small proportion. How to improve the polarization of the p53-SLP vaccine-induced T-cell response should be focused in future trials (75). Balint et al. observed the decreased Treg to Teff cell ratio in samples from three of five patients and increased cytolytic $\mathrm{T}$ cell responses after immunizations in a phase $1 / 2$ clinical trial of advancedgeneration Ad5 [E1-, E2b-]-CEA(6D) vaccine in mCRC patients. After a long-term follow-up, $20 \%$ of patients were still alive, with median survival of 11 months (79). Morse et al. demonstrated that patients produced less neutralizing antibodies and more CEA-specific $\mathrm{T}$ cell responses when using VRP as vectors in a phase I/II study. In a further study, the 5-year RFS was $75 \%$ in patients with stage III cancer (95\%CI 40 to $91 \%$ ) and no one died. CD8+ $\mathrm{T}_{\mathrm{EM}}$ increased and FOXP3 + Tregs decreased in $83 \%$ patients $(10 / 12)$ after vaccination treatment. The results suggested that VRP-CEA may prolong the OS in stage III CRC patients $(76,80)$. A Randomized Clinical Trial reported that PFS and OS of mCRC patients in the modified vaccinia Ankara-5T4 (MVA-5T4) treatment group was significantly prolonged, compared with those in the no treatment group (5.6 months vs 2.4 months, $\mathrm{P}<.001 ; 20.0$ vs 10.3 months; $\mathrm{HR}, 0.32$; 95\% CI, 0.14 $0.74 ; \mathrm{P}=.008)$.In addition, baseline anti-5T4 responses was doubled in 16 of 35 mCRC patients treated with MVA-5T4 (81). It is worth mentioning that the vaccine with poxvirus vectors highlights a critical component of vaccine therapy. Poxvirus vectors can be used to incorporate multiple transgenes and its safety has been increasingly proven. In a pilot study of 25 patients treated with a poxviral vaccine regimen targeting CEA and MUC-1, along with a triad of costimulatory molecules engineered into vaccinia (PANVAC-V) as a prime vaccination and into fowlpox (PANVAC-F) as a booster vaccination, the vaccine was tolerable and nine of 16 patients achieved immune responses to MUC-1/CEA (77). A randomized phase II study further study the therapeutic effect of vaccines based on dendritic cells (DCs) and poxvectors targeting CEA and MUC1 (PANVAC) in resected mCRC patients. Patients $(n=74)$ were randomized to injections of autologous DCs modified with PANVAC (DC/PANVAC) or PANVAC with per injection GM-CSF. Two-year recurrence-free survival in DC/PANVAC and PANVAC/GM-CSF group was 47 and $55 \%$ respectively $(\mathrm{P}=0.48)$. In addition, the vaccinated patients have better survival than the unvaccinated group (78). An open-label, $3+3$ design, dose-escalation trial proved the safety and potential clinical activity of a new poxviral-based vaccine (BN-CV301), comprised of recombinant (rec.) modified vaccinia Ankara (MVA-BN-CV301; prime) and rec. fowlpox (FPV-CV301; boost) (74).

There are also new tumor-associated antigens being developed for use in vaccine therapy. A phase 2 study was performed to test the efficacy of tecemotide (an antigenspecific cancer vaccine inducing immunity against mucin-1). There is no significant difference in RFS and 3-year OS rate between mCRC patients after resection of CRLM treated with tecemotide and those treated with placebo (82). Accumulated abundant insertion/deletion mutations in dMMR cancer cells at microsatellites resulted in the production of immunogenic frameshift peptide (FSP) neoantigens. Kloor et al. performed a clinical phase I/IIa trial of FSP-based vaccine in dMMR CRC. All patients achieved humoral and cellular immune responses induced by the vaccine. However, only two patients (9\%, two of 22 patients) achieved stable disease as best overall response. Among them, stable disease and stable CEA levels ( $\geq 7$ months) 
TABLE 2 | Summary of Vaccine Treatment for mCRC.

\begin{tabular}{|c|c|c|c|c|c|c|}
\hline Study & Phase & Agent & Population & $\begin{array}{l}\text { MSI } \\
\text { status }\end{array}$ & Endpoint & Reference \\
\hline NCT01147965 & $1 / 2$ & AD5-CEA Vaccine & $32 \mathrm{mCRC}$ & - & $\begin{array}{l}\text { The primary purpose: } \\
\text { determine the safety } \\
\text { The secondary objectives: } \\
\text { evaluate CEA-specific immune responses and clinical } \\
\text { response rate }\end{array}$ & $(68)$ \\
\hline NCT00529984 & 2 & AVX701 (VRP-CEA Vaccine) & $\begin{array}{l}28 \text { metastatic } \\
\text { tumors; } \\
\text { including } 21 \mathrm{mCRC}\end{array}$ & - & $\begin{array}{l}\text { the primary objectives: } \\
\text { determine the safety } \\
\text { The secondary objectives: } \\
\text { evaluate CEA-specific immune responses and clinical } \\
\text { response rate }\end{array}$ & (69) \\
\hline NCT01890213 & 2 & AVX701 (VRP-CEA Vaccine) & 12 Stage III CRC & - & - & $(70)$ \\
\hline NCT00154713 & 1 & CEA-pulsed DC & $12 \mathrm{mCRC}$ & - & $\begin{array}{l}\text { The primary endpoint: } \\
\text { safety }\end{array}$ & $(74)$ \\
\hline NCT01462513 & 2 & Tecemotide (L-BLP25) or placebo & $\begin{array}{l}121 \text { mCRC with } \mathrm{RO} / \\
\mathrm{R} 1 \text { resection }\end{array}$ & & $\begin{array}{l}\text { The primary endpoints: } \\
\text { RFS and 3-year overall survival (OS) rate; } \\
\text { The secondary endpoints: } \\
\text { RFS and OS in subgroups with different MUC1 } \\
\text { expression and safety }\end{array}$ & $(72)$ \\
\hline NCT01461148 & $1 / 2 a$ & FSP-based vaccine & $22 \mathrm{CRC}$ & MSI & $\begin{array}{l}\text { The primary endpoints: } \\
\text { safety (phase I) and immunogenicity (phase lla); } \\
\text { The secondary endpoints: } \\
\text { tumor response (both phases) and immunogenicity } \\
\text { (phase I) and safety (phase lla) }\end{array}$ & (73) \\
\hline NCT00027833 & 2 & $\begin{array}{l}\text { ALVAC-CEA-B7.1 vaccine + FOLFIRI; } \\
\text { FOLFIRI + ALVAC-CEA-B7.1 vaccine; } \\
\text { ALVAC-CEA-B7.1 vaccine + tetanus } \\
\text { toxoid + FOLFIRI }\end{array}$ & $180 \mathrm{mCRC}$ & - & $\begin{array}{l}\text { The primary endpoints: } \\
\text { Immune response to the vaccine. }\end{array}$ & $(75)$ \\
\hline NCT00676949 & 1 & $\begin{array}{l}5 \text { peptide vaccines of KOC1, TTK, CO16, } \\
\text { DEPDC1, MPHOSPH1 }\end{array}$ & $\begin{array}{l}18 \text { metastatic } \\
\text { Tumors, } \\
\text { including nine } \\
\text { mCRC }\end{array}$ & - & $\begin{array}{l}\text { The primary end point: } \\
\text { safety and tolerability. } \\
\text { The secondary endpoints: } \\
\text { MTD and immune response }\end{array}$ & $(76)$ \\
\hline NCT01413295 & 2 & DC vaccine + BSC or BSC alone & $52 \mathrm{mCRC}$ & - & $\begin{array}{l}\text { The primary endpoints: } \\
\text { PFS; } \\
\text { The secondary endpoints: } \\
\text { PFS, OS, toxic effects, and ORR. }\end{array}$ & $(77)$ \\
\hline NCT01348256 & 2 & DC vaccine & $19 \mathrm{mCRC}$ & - & - & (78) \\
\hline- & $1 / 2$ & p53-SLP & $10 \mathrm{mCRC}$ & - & - & (67) \\
\hline- & & $\begin{array}{l}\text { MVA-5T4, } \\
\text { metronomic low-dose } \\
\text { cyclophosphamide, } \\
\text { or a combination of both treatments }\end{array}$ & $55 \mathrm{mCRC}$ & - & $\begin{array}{l}\text { The primary endpoints: } \\
\text { magnitude of 5T4-specific responses at treatment } \\
\text { day 43; The secondary end points: } \\
\text { the kinetics of anti-5T4 immune responses overtime, } \\
\text { PFS, OS }\end{array}$ & (71) \\
\hline- & 2 & TroVax(MVA-5T4) & $19 \mathrm{mCRC}$ & - & - & (79) \\
\hline- & 2 & a peptide vaccine combined with UFT/LV & 46 stage III CRC & - & $\begin{array}{l}\text { The primary end point: } \\
\text { RFS; } \\
\text { The secondary endpoints: } \\
\text { OS, safety, tolerability and peptide-specific activities }\end{array}$ & (80) \\
\hline- & & DC vaccine & $46 \mathrm{mCRC}$ & - & - & (81) \\
\hline
\end{tabular}

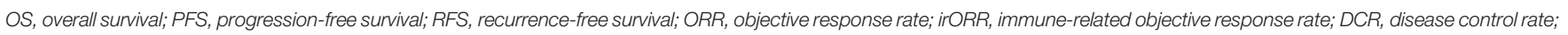

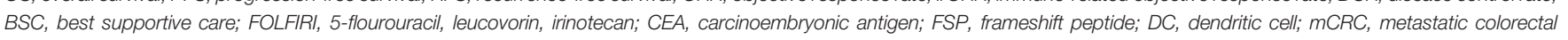
cancer; MSI-(H), microsatellite instability-(high); MSS, microsatellite stable.

was observed in a severely metastatic patient received extensive treatment (83).

What is the effect of a combination of vaccine and chemotherapy? Kaufman et al. conducted a study to assess whether systemic chemotherapy can affect the on T-cell immunity induced by ALVAC-CEA/B7.1 vaccine in mCRC patients. The vaccine was injected before and after treatment with 5-fluorouracil, leukovorin and irinotecan. The generation of CEA-specific T-cell responses following vaccination was not affected by systemic chemotherapy, with no differences in clinical or immune response across the treatment groups (84). Similar results were found in another study of MVA-5T4 (TroVax) and systemic chemotherapy in 19 mCRC patients (85). The benefits of the vaccine combined with chemotherapy for patients have been further confirmed in subsequent studies. HLA-A2402+ patients with advanced solid tumors (nine colorectal cancer) were treated with vaccine composed of five HLA-A2402-restricted, tumor-associated antigen (TAA) epitope 
peptides, following by escalating doses of cyclophosphamide. After treatment of cyclophosphamide, regulatory T cells baseline was decreased. TAA-specific $\mathrm{T}$ cell responses were significantly collected to longer overall survival (86). A similar phase II clinical trial of a peptide vaccine combined with UFT/LV as adjuvant treatment was performed in patients with stage III CRC. Three-year RFS rate was $85.7 \%$ in patients with positive CTL responses in the HLA-A ${ }^{\star} 2402$ matched group, compared with $33.3 \%$ in those without $(\mathrm{HR}=0.159,95 \% \mathrm{CI}: 0.023-0.697$; $\mathrm{P}=$ 0.011 ), although there was no significant difference in three-year RFS between HLA-A ${ }^{\star} 2402$ matched and unmatched groups (67.8 vs. $73.6 \%$, respectively; $\mathrm{HR}=1.254,95 \% \mathrm{CI}: 0.48-4.63 ; \mathrm{P}=$ 0.706) (87).

Because dendritic cell cells (DCs) are the most effective antigen-presenting cells, it is possible to exploit their diversity to produce improved therapeutic vaccines. Many therapeutic vaccination routes against cancer are being developed clinically. Twenty-six colorectal patients received DCs treatment after resection of the metastatic lesion. 5-year RFS rate was $63 \%$ in patients with evidence of a vaccine-induced immune response 1 week after vaccination, compared with $18 \%$ in nonresponders $(\mathrm{P}=$ 0.037) (88). In another phase II trial, pre-treated mCRC patients were randomly assigned to receive autologous tumor lysate dendritic cell vaccine (ADC) + best supportive care (BSC) (experimental arm [EA]) or BSC (control arm [CA] alone. No one in EA achieved objective radiological response. Median PFS was 2.7 months (95\% CI, 2.3-3.2 months) and 2.3 months (95\% CI, 2.12.5 months) ( $\mathrm{p}=0.628$ ), median OS was 6.2 months (95\% CI, 4.47.9 months) and 4.7 months (95\% CI, 2.3-7 months) in the CA vs. EA group $(p=0.41)$, respectively. OS in responders was 7.3 months (95\% CI, 5.2-9.4 months), compared with 3.8 months (95\% CI, 0.66.9 months) in non-responders $(\mathrm{p}=0.026)$. The results mean that patients don't benefit from ADC, although ADC-induced tumorspecific immune response was observed in patients (89). However, Rodriguez et al. reported that $\mathrm{mCRC}$ patients who received the DC vaccine as postoperative adjuvant therapy were less likely to relapse, with median DFS of 25.26 months in the vaccine arm versus 9.53 months of months in the observation arm (90). Dendritic cell vaccines that target specific tumor-associated antigens may further enhance the effectiveness of immunotherapy. In twelve patients treated with CEA-pulsed DCs mixed with tetanus toxoid and subsequent interleukin-2, two patients had stable disease and 10 patients showed disease progression, suggesting that a small proportion of patients had clinical benefit (91). In another phase I study of DC vaccination targeting WT1 for resectable advanced CRC patients, patients achieved lasting immunity from DC vaccination ( $\geq 2$ years) and prolonged survival (92).

In addition to developing a variety of vaccines, the corresponding vector is also under continuous research to better enhance the immune response. Adenovirus serotype 5 (Ad5), as a common viral vector, is often used to prepare vaccines against pathogens and tumor antigens. However, AD5-induced virus-specific neutralizing antibodies appear after exposure to an AD5-based vaccine, limiting transgenic transmission and target-specific immunity. Flickinger et al. reported that more patients $(\geq 90 \%)$ with Ad5.F35-based vaccines targeting tumor antigens achieved clinically relevant immune responses, compared with approximately $50 \%$ patients with Ad5-based vaccines (93).

Attempts to confirm the efficacy of the vaccine for mCRC through multiple ways (e.g., dendritic cells, autologous tumor cells, recombinant viral vectors, and peptides) appear to have failed, with limited clinical efficacy and outcomes, despite improved specific immune responses.

\section{The Combination of Immunotherapy and Targeted Therapy}

In recent years, a variety of targeted therapies led by antiangiogenic drugs have been increasingly used in the clinical treatment of various tumors. In addition to their excellent antiangiogenic effects, they also have immune-enhancing effects. Manzoni et al. found that patients responded to bevacizumab showed a trend of increasing CD3 $(p=0.07)$ and CD4 $(p=0.05)$ (94). By analyzing immune cell infiltration in the liver metastatic sites of 53 colorectal cancer patients treated with chemotherapy plus cetuximab, chemotherapy without cetuximab, and no chemotherapy before operation, Inoue et al. reported that the chemotherapy with cetuximab group had a higher infiltration of $\mathrm{CD} 3+(\mathrm{P}=0.003), \mathrm{CD} 8+(\mathrm{P}=0.003)$ and $\mathrm{CD} 56+(\mathrm{P}=0.001)$ cells, compared with other groups (95). This opens up new possibilities to further improve clinical outcomes in combination with immunotherapy, especially for immunotreatment-resistant MSS tumors. A single arm, multi-center phase II study (CAVE Colon) was conducted to study the efficacy of avelumab and cetuximab in RAS WT mCRC patients treated with a first-line CT in combination with an anti-EGFR agent with a major response achieved (complete or partial). We are looking forward to its clinical trial results (96). In another single arm phase II AVETUX trial, 43 RAS/BRAF wildtype mCRC pts (40 MSS) received the treatment of mFOLFOX6 and cetuximab combined with avelumab. The ORR and DFS were 79.5 and $92.3 \%$ respectively. Among them, 6 pts had CR and 25 pts had PR.; 2 pts had progression and 1 was not evaluable. In addition, $79.5 \%$ patients achieved early tumor shrinkage (ETS) ( $\geq 20 \%$ after 8 weeks). In short, The AVETUX regimen is feasible and produces a high response rate in MSS patients, mainly occurring in the first 8 weeks (97). However, 445 BRAFwt mCRC pts in MODUL study who received 16 weeks of induction treatment with FOLFOX + BEV were randomized to take medication of $\mathrm{FP} / \mathrm{BEV}+$ atezolizumab (297 pts) or FP/BEV (148 pts). At a median follow-up of 10.5/18.7 months there was no significant difference in PFS and OS. Adding atezolizumab to FP/BEV as a first-line treatment did not benefit BRAFwt mCRC patients (98). Recently, MEK inhibitors have received increasing attention, particularly in the area of combined immunotherapy, whose efficacy has been evaluated in multiple clinical trials. In a phase I/Ib study of MEK inhibitor (cobimetinib) and PD-L1 inhibitor (atezolizumab) in patients with solid tumors (mCRC; $\mathrm{n}=84$ ), $8 \%$ mCRC patients (seven of 84 patients) achieved confirmed responses, independent of KRAS/ BRAF status across diseases. However, potential collaborative activity observed in mCRC disappeared in a further phase III study (99). Due to the potential to induce antibody-dependent cell-mediated cytotoxicity (ADCC), stimulation of NK cells represents another ideal target for this molecular approach. In 
LOVO xenograft tumor models with positive EGFR expression, the combination of cetuximab and NK cells showed great antitumor effect (100). Similarly, cetuximab enhanced the cytotoxic activity of NK cells on EGFR+ tumor cells independent of RAS status (101).

\section{The Combination of Immunotherapy and Chemotherapy}

Tumor associated antigens, such as CEA and other specific molecules, tend to be overexpressed as chemotherapeutic drugs kill tumor cells. Meanwhile, death signaling induced by tumor antigen-specific cytotoxic T lymphocytes during chemotherapy moderates tumor cell resistance. These provide a theoretical basis for the combination of chemotherapy and immunotherapy. In a phase II trial, CRC patients were administered subcutaneously granulocyte macrophage colony-stimulating factor and low-dose interleukin-2, following gemcitabine + FOLFOX-4 (oxaliplatin, fluorouracil, and folinic acid) polychemotherapy. At a median follow up of 12.5 months, the ORR and DCR were as high as 68.9 and $96.5 \%$, respectively. Analysis of peripheral blood mononuclear cells (PBMCs) in 20 patients showed that immune response to colon carcinoma antigen increased and suppressive regulatory $\mathrm{T}$ lymphocytes (CD4+CD25T-reg+) decreased significantly (102). Subsequent multicenter phase II and phase III clinical trials were conducted to further assess the combination (GOLFIG) in mCRC patients. In the phase II trial (GOLFIG-1 trial), including $46 \mathrm{mCRC}$ patients who have had previous chemotherapy, RR and DCR were 56.5 and $91.3 \%$, respectively, with a mean PFS of 12.3 months (103). In the phase III trial (GOLFIG-2), 124 mCRC patients were randomly assigned in a $1: 1$ ratio to receive the GOLFIG regimen or FOLFOX-4 regimen for the 1st line setting. Significant difference in $\mathrm{RR}(66.1 \%$ vs. $37.0 \%, \mathrm{P}=0.002)$, DCR, and PFS (9.23 vs. 5.70 months; $\mathrm{P}=0.002$ ) indicated that GOLFIG chemoimmunotherapy is markedly better than FOLFOX regimen for first-line treatment of mCRC (104). Caraglia et al. then retrospectively analyzed $179 \mathrm{mCRC}$ patients in these two trials and followed them up for 15 years. Median PFS and OS were 15.28 (95\% CI: 10.36-20.20) and 24.6 (95\% CI: 19.07-30.14) months, respectively, To note, 14 patients survived for 10 years without disease progression (105). In their latest investigation of the GOLFIG-2 trial, patients in the GOLFIG group tend to achieve longer OS and PFS than those in the FOLFOX group $(\mathrm{HR}=$ $0.69, \mathrm{P}=0.06 ; \mathrm{HR}=0.58, \mathrm{p}=0.006)$. Their analysis also confirmed that pretreated patients had significant antitumor response, with a mean PFS of 12.55 (95\% CI: 7.19-17.9) and OS of 20.28 (95\% CI: 14.4-26.13) months, respectively. The GOLFIG regimen may be a reliable therapeutic option for pre-treated mCRC patients.

The above sequential clinical trials initially demonstrated the efficacy of chemotherapy combined with immunotherapy. The effect of chemotherapy on immune cells has been studied more and more. Roselli et al. analyzed mononuclear cell subsets from peripheral blood in mCRC patients $(n=23)$ before and during treatment with FOLFIRI plus bevacizumab. Despite differences among patients, most patients experienced small changes in the ratio of CD4(+) T cells to regulatory T cells (Treg) or small changes in Treg inhibitory activity during treatment. Tregs in responders to the chemotherapy was significantly decreased during therapy $v s$. pretherapy compared with non-responders (106). In the same way, Scurr et al. observed a reduction in the percentage and absolute number of Treg in peripheral blood-derived lymphocytes from cyclophosphamide-treated mCRC patients. Cyclophosphamide significantly enhanced IFN $\gamma+$ tumor-specific T-cell responses and markedly delayed tumor growth in mCRC patients. [HR $=0.29 ; 95 \%$ CI, 0.12-0.69; P = 0.0047), compared with nonresponders and notreatment controls (107). However, Dagenborg et al. reported that intratumoral T-cell densities was not associated with neoadjuvant chemotherapy therapy (NACT) before surgery in $45 \mathrm{mCRC}$ patients. What is noteworthy is that intratumoral T-cell densities increased significantly in a short period of time aftertreatment, $<9.5$ weeks $v s$ $>9.5$ weeks (medians 491, 236 cells $/ \mathrm{mm}^{2}$, respectively; $\mathrm{P}<.0001$ ). The results indicated that intratumoral T-cells may increase only for a short time after NACT administration, and the best combination of chemotherapy and immunotherapy should be further investigated (108). The relationship between chemotherapy and tumor PDL1 expression has also received more and more attention. Huang et al. found that expression of tumor PD-L1 and other immune-related genes were enhanced by decitabine (DAC)-induced DNA hypomethylation and intratumoral $\mathrm{T}$ cell infiltration increase in vitro and in vivo (109). Further, tumor samples from mCRC patients received Folfox regimen showed induction of PD-L1 expression and high CD8 T cell infiltration (110).

Other studies have shown that chemotherapy has a negative effect on immunotherapy. Bruni et al. reported that chemotherapy accelerates the aging of $V \delta 2$ pos $T$ cells in CLM patients,which is non-classical lymphocytes possessing a wide range of anti-tumor activities (111). In 15 refractory mCRC patients treated with AMP-224 in combination with SBRT and lowdose cyclophosphamide, no one achieved objective response and three patients $(20 \%)$ had stable disease. Patients did not benefit from the combination, with median PFS of 2.8 months (95\%CI, 1.2-2.8 months) and OS of 6.0 months (95\% CI, 2.8-9.6 months), respectively (112). Standard-of-care treatment seems to be harmful to early-stage CRC patients with high PD-L1 expression $(\mathrm{HR}=4.95 ; \mathrm{CI}, 1.10-22.35)$, suggesting that standard chemotherapy should not be used in stage II/III colorectal carcinoma patients with PD-L1 (high)/MSI/immune (high) (113).

\section{The Combination of Immunotherapy and Ablation}

Ablation, as one of the established effective methods for resectable liver metastases from colorectal cancer, can also elicit tumor antigen-specific $\mathrm{T}$ cell responses and enhance the efficacy of immunotherapy. It can lead to tumor regression in untreated lesions, known as abscopal effect. This occurs because a variety of harmful molecules are released during ablation, including tumorassociated antigens, inflammatory cytokines, etc. In mouse models, we observed that incomplete radiofrequency ablation (iRFA) promotes tumor growth and impedes the efficacy of anti-PD-1 therapy. Mechanistically, more myeloid suppressor cells infiltrated into the local persistent inflammatory areas caused by iRFA, resulting in the inhibition of $\mathrm{T}$ cell function in tumors (114). Lemdani et al. demonstrated that TIL in metastatic lesion of patients and in mice model did not increase after RFA and RFA 
could not prevent recurrence. By adding systemic PD-1 blockade, immune deficiency in large secondary lesions can be reversed. In the situation of large lesions that do not respond to single RFA, the use of ICIs in metastatic MSS CRC may be reconsidered (115). Consistent with the above results, immunohistochemistry showed immune cells in metastatic lesions did not increase in six patients after RFA treatment, although induced immune responses and/or pre-existing $\mathrm{T}$ cell immunity against the specific targets was observed (116). Shi et al. reported that PD-L1-PD-1 axis plays a key role in inhibiting the antitumor immune responses induced by RFA. Not only T-cell infiltration, but also PD-L1 expression in primary human colorectal tumors increased after RFA treatment of liver metastases. Significantly enhanced T-cell immune responses, stronger antitumor immunity and prolonged survival were observed in mice model after the combined therapy of RFA and anti-PD-1 antibodies. This indicates the rationality and feasibility of ablation combined with immune checkpoint therapy for mCRC patients (117).

\section{The Combination of Immunotherapy and Radiotherapy}

Another hot area of tumor immunotherapy is the use of monoclonal antibodies to deliver cytotoxic substances directly to the tumor site, known as radioimmunotherapy (RIT), which can increase the toxic dose of the tumor site and reduce the damage to the surrounding normal tissue. In a phase II study, 23 patients received RAT with radiolabeled anti-CEA antibodies after surgery for LM of CRC. At a median follow-up of 64 months, median OS and median DFS from initial hepatectomy for RAT patients was 68.0 months (95\% CI, 46.0 months to infinity) and 18.0 months (95\% CI, 11.0 to 31.0 months), with 5year survival rate of $51.3 \%$. Historical and contemporaneous controls without RAT were analyzed, adjuvant RAT seem to improve survival for CRC patients undergoing complete LM resection (118). Over a longer period of follow-up, Liersch et al. found 3- and 5-year survival rate of 68.4 and $42.1 \%$ for patients with RAT, compared with 36.8 and $15.8 \%$ for the controls (119). Some 13 patients are receiving the same type of RIT after complete resection of liver metastases (LM) from colorectal cancer. At a median follow-up of 127 months, median DFS and OS are 12 and 50 months, respectively (120). RIT targeting other antigen also showed safety and feasibility for 19 patients, with one patient of partial response, and 10 patients of stable disease (121). Studies have also evaluated the efficacy of RIT in combination with other treatments. The combination of cetuximab and RIT targeting CEA significantly reduced tumor growth and prolonged survival of mice than RIT monotherapy (122). Chen et al. demonstrated that RIT significantly increased PD-L1 expression on T cells. RIT plus PD-L1 blockade improved local tumor control, overall survival and avoid relapse, with expanded infiltration of CD8+ T cells (123).

\section{OTHER TYPES OF IMMUNOTHERAPY}

Many experiments are also investigating the possibility of other molecules as future immunotherapies.
TGF- $\beta$ is a kind of can influence a variety of cellular events and therefore has a dual role. On the one hand, this cytokine can block the ability of tumor cells to multiply by interfering with key molecules (CDK4, CDKI) in the cell cycle during the initial stages of cancer. On the other hand, TGF- $\beta$ promotes tumor growth and metastasis as the tumors progress to an advanced stage (124). Many studies have demonstrated that blocking TGF-b signaling reduced metastasis in CRC and other solid tumors (125). Tauriello et al. discovered the significant role of TGF- $\beta$ in the immune system for metastasis CRC. Increased TGF $\beta$ in the tumor microenvironment promoted immune evasion by decreasing $\mathrm{T}$-cell infiltration and inhibiting acquisition of the TH1-effector phenotype. In the quadruple-mutant mice model bearing metastatic intestinal tumors with TGF $\beta$-activated stroma, inhibition of TGF $\beta$ prevented metastasis by enhancing cytotoxic $\mathrm{T}$-cell response against tumor cells, while the use of anti-PD1 drug drew finite efficacy. Furthermore, combination of TGF $\beta$ inhibitor and antiPD1 drug had excellent effect in mice with severely hepatic metastases (126). Immunotherapies targeting TGF $\beta$ signaling and the combination with ICIs may therefore be potential and promising options for advanced CRC patients.

CC chemokines consist of 28 chemotactic cytokines crucial to all kinds of immune system cells, including CD4+ and CD8+ lymphocytes, dendritic cells, eosinophils, macrophages, monocytes, and NK cells. At the same time, they are essential in the development of tumors (127).

Halama et al. found that tumor-infiltrating lymphocytes delivering CCL5 are abundant in the invasive margin of hepatic metastatic samples from CRC patients, which instead promotes the growth and dissemination of tumor by polarizing macrophages to pro-tumoral phenotype via CCR5. Blocking CCR5 repolarized the macrophages to exert the anti-tumor efficiency in vitro organoid models, which was further confirmed in a phase I trial of CCR5 antagonist in refractory mCRC patients (128). Zhang et al. demonstrated that the lack of CCL5 inhibited tumor growth and metastasis by enhancing CD8+ T cells infiltration into tumor areas in CRC mouse models. Meanwhile, the absence of CCL5 could increase the PD-1 and PD-L1 expression and alleviate the resistance to ICIs in CRC mouse model. Clinical specimen from CRC patients also confirms the results (129). Same changes of immune-related molecules (CCR5, CCL5, PD1, PD-L1) in the microenvironment of hepatic metastases were also showed by Suarez-Carmona et al. By further analyzing two available cohorts, the data showed that patients with low gene expression of CCR5 in metastases had prolonged DFS (130). The study above suggests that targeting CCL5-CCL5 axis monotherapy or in combination with ICIs may be a possible therapeutic strategy for CRC and need to be tested in future trials.

Many studies have been looking at Toll-like receptors (TLRs) due to the ability of stimulating antitumor immunity by initiating innate and adaptive immune responses (131). 28 patients with metastatic solid tumors received a novel synthetic DNA-based tolllike receptor 9 (TLR9)-immunomodulator. In 15 patients completing the treatment cycle, six (40\%) had stable disease (SD). NK cells, DCs and B cells were transiently increased, although there were no changes in the composition and activation status of various kinds of $\mathrm{T}$ cells (helper $\mathrm{T}$ cells, cytotoxic T cells, naive and memory T cells) (132). Sorski et al. 
found that the percentage of NK cells in marginating-hepatic $(\mathrm{MH})$ cells was high in BALB/c mice, but the cytotoxicity was weak. However, TLR-9 agonist (CpG-C) treatment increased $\mathrm{MH}$ NK cell numbers and activities in the mice model with mCRC, with increased maturation markers (NKp46, CD11b) and decreased the inhibitory NKG2D (133). In the murine colon metastatic cancer models, entolimod (TLR5 agonist) induces a large number of NK cells to migrate from blood and bone marrow to the liver (134). Then, we observed CD8(+) T-cell response following the activation of DCs depending on NK cells. Therefore, entolimod provoked tumor specific and persistent immune memory. TLR5 agonists can be used as efficient antitumor vaccine without the need to identify tumor-specific antigens. However, Zheng et al. found TLR ligands (TLR4, TLR5) released by nonvirulent tumor-targeting bacteria played a prominent part in tumor suppression in mouse models (135).

\section{CONCLUSION}

In general, we are developing a variety of immunotherapies and achieved some successes in the field of immunotherapy, especially for mCRC patients with dMMR (Figure 3). However, for one thing, the response rate of these patients is still not high enough, and for another, there is no effective treatments including immunotherapy for other mCRC patients with MSS yet. First, ICIs are well researched, and there are already drugs approved for clinical use. Now, due to the relatively good advantages of molecular targeted therapies, more consideration should be given to the combination of ICIs and molecular targeted therapies (136). A small number of clinical trials have shown its potential with increased response rate and better prognosis, and more trials are underway and planned (Table 3). The results are worth waiting for. Secondly, few studies of ACT have been
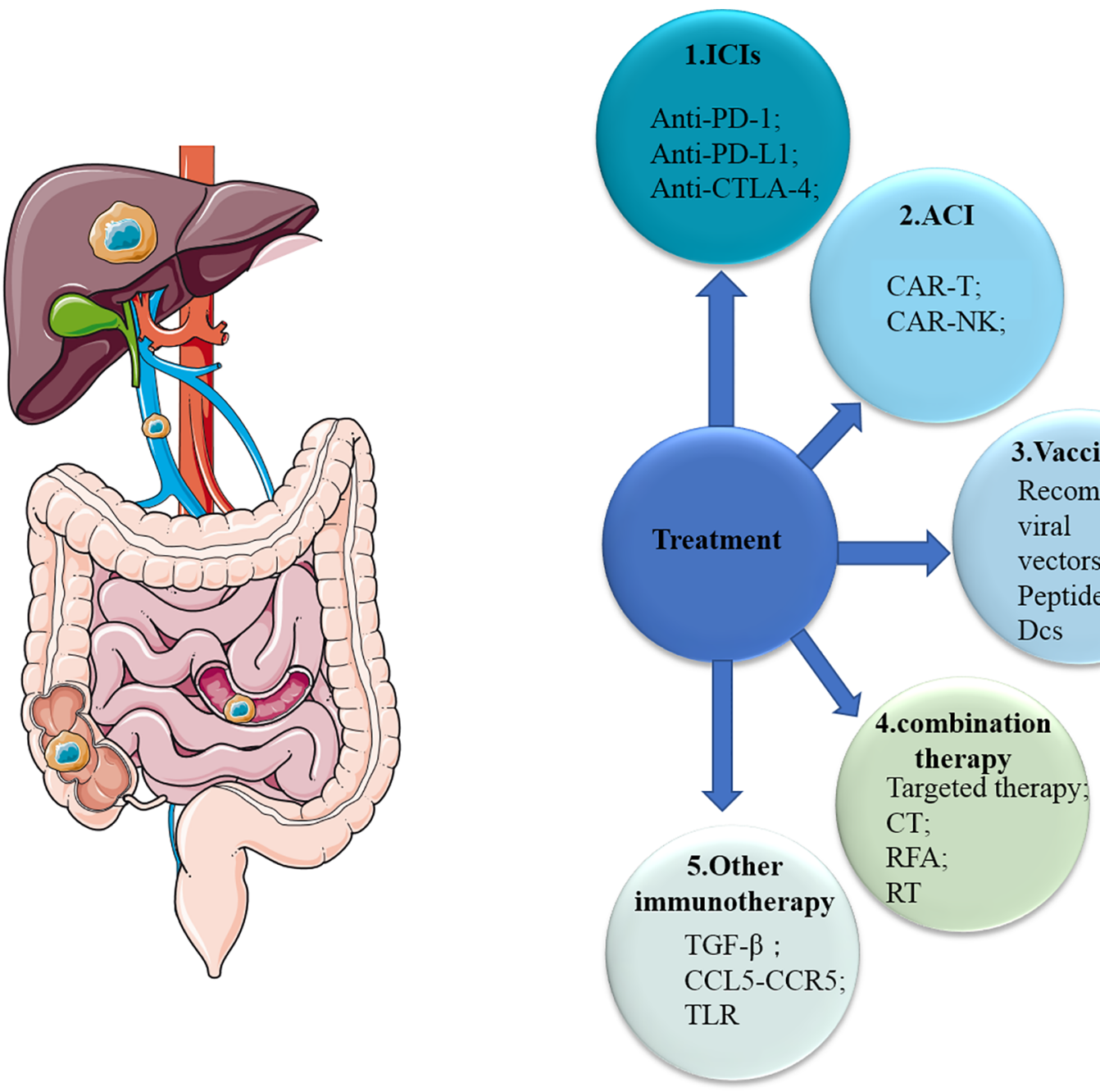

FIGURE 3 | Overview of therapies for mCRC. mCRC, metastatic colorectal cancer; ICls, immune checkpoint inhibitors; ACl, adoptive cellular immunotherapy; CT, chemotherapy; RFA, radiofrequency ablation; RT, radiotherapy; CTLA-4, cytotoxic T-lymphocyte-associated protein 4; PD-1, programmed cell death 1; PD-L1, PD-1 ligand; Treg, regulatory T cell; DC, dendritic cell; NK cell, natural killer cell; TLR, toll-like receptor. 
TABLE 3 | Ongoing or Future Clinical Trials of Immunotherapy for mCRC.

\begin{tabular}{|c|c|c|c|c|c|}
\hline Study & Phase & Agent & Population & Status & Endpoint \\
\hline NCT03721653 & 2 & $\begin{array}{l}\text { FOLFOXIRI + Bevacizumab + atezolizumab vs FOLFOXIRI + } \\
\text { Bevacizumab }\end{array}$ & $201 \mathrm{mCRC}$ & - & $\begin{array}{l}\text { The primary end point: } \\
\text { DCR; } \\
\text { The secondary endpoints: } \\
\text { PFS, ORR, OS }\end{array}$ \\
\hline NCT03202758 & $1 / 2$ & Durvalumab + Tremelimumab + FOLFOX & $48 \mathrm{mCRC}$ & - & $\begin{array}{l}\text { The primary end point: } \\
\text { safety }\end{array}$ \\
\hline NCT04072198 & 2 & Nivolumab + FOLFOXIRI/Bevacizumab & $\begin{array}{l}70 \\
\text { advanced } \\
\text { CRC }\end{array}$ & RASm/BRAFm & $\begin{array}{l}\text { The primary end point: } \\
\text { ORR; } \\
\text { The secondary endpoints: } \\
\text { OS }\end{array}$ \\
\hline NCT03186326 & 2 & $\begin{array}{l}\text { Avelumab versus a standard second-line chemotherapy plus a } \\
\text { targeted agent according to tumor RAS status }\end{array}$ & $132 \mathrm{mCRC}$ & $\mathrm{MSI} / \mathrm{dMMR}$ & $\begin{array}{l}\text { The primary end point: } \\
\text { median PFS; } \\
\text { The secondary endpoints: } \\
\text { ORR, OS, quality of life and toxicity }\end{array}$ \\
\hline NCT03827044 & 3 & Avelumab + 5-FU Based Chemotherapy & $\begin{array}{l}402 \text { stage } \\
3 \mathrm{CRC}\end{array}$ & $\begin{array}{l}\text { MSI-High or } \\
\text { POLE Mutant }\end{array}$ & $\begin{array}{l}\text { The primary end point: } \\
\text { DFS }\end{array}$ \\
\hline NCT04062721 & 1 & $\begin{array}{l}\text { Local Immunomodulation (TLR agonist and GM-CSF) + } \\
\text { Radiofrequency Ablation }\end{array}$ & $50 \mathrm{mCRC}$ & unresectable & $\begin{array}{l}\text { The primary endpoints: } \\
\text { PFS rate at } 12 \text { months; } \\
\text { The secondary endpoints: } \\
\text { median PFS; response rate; OS }\end{array}$ \\
\hline NCT04513431 & 1 & Anti-CEA-CAR T & $18 \mathrm{mCRC}$ & - & $\begin{array}{l}\text { The primary endpoints: } \\
\text { adverse effects including cytokine storm } \\
\text { response and any other adverse effects }\end{array}$ \\
\hline NCT03698461 & 2 & Atezolizumab versus Atezolizumab + Bevacizumab + FOLFOX & $20 \mathrm{mCRC}$ & - & \\
\hline NCT04030260 & 2 & Regorafenib + Nivolumab + Radiotherapy & $43 \mathrm{mCRC}$ & pMMR/MSS & $\begin{array}{l}\text { The primary endpoints: } \\
\text { PFS rate at } 6 \text { months; } \\
\text { The secondary endpoints: } \\
\text { objective response; DCR; OS }\end{array}$ \\
\hline NCT04599140 & $1 / 2$ & SX-682 + Nivolumab & $53 \mathrm{mCRC}$ & $\begin{array}{l}\text { RAS Mutated; } \\
\text { MSS }\end{array}$ & $\begin{array}{l}\text { The primary end point: } \\
\text { safety; } \\
\text { The secondary endpoints: } \\
\text { ORR }\end{array}$ \\
\hline NCT03202758 & $1 / 2$ & Durvalumab + Tremelimumab + FOLFOX & $48 \mathrm{mCRC}$ & - & $\begin{array}{l}\text { The primary end point: } \\
\text { PFS; } \\
\text { The secondary endpoints: } \\
\text { OS }\end{array}$ \\
\hline NCT02754856 & 1 & Durvalumab + Tremelimumab & $26 \mathrm{mCRC}$ & - & $\begin{array}{l}\text { The primary end point: } \\
\text { safety and feasibility; } \\
\text { The secondary endpoints: } \\
\text { RFS }\end{array}$ \\
\hline
\end{tabular}

OS, overall survival; PFS, progression-free survival; DFS, disease-free survival; RFS, recurrence-free survival; ORR, objective response rate; irORR, immune-related objective response rate; $D C R$, disease control rate; BSC, best supportive care; $P D-1$, programmed cell death 1; PD-L1, programmed cell death ligand-1; CTLA-4, cytotoxic T-lymphocyte-associated protein 4; 5-FU/LV, 5-flourouracil, leucovorin; FOLFOX, 5-flourouracil, leucovorin, oxaliplatin; FOLFIRI, 5-flourouracil, leucovorin, irinotecan; mCRC, metastatic colorectal cancer; FOLFOXIRI, 5flourouracil, leucovorin, oxaliplatin, irinotecan; MSI-(H), microsatellite instability-(high); MSS, microsatellite stable; TLR, toll-like receptor; CEA, carcinoembryonic antigen.

conducted in mCRC patients, although ACT has long been used in patients with hematological malignancies due to its excellent efficacy. We should explore more of its possibilities in mCRC patients, especially with regard to NK cell therapy. Thirdly, despite many studies, cancer vaccines have not made major breakthroughs in mCRC patients because of its limited role and possible safety issues. The cancer vaccines may be used more as an adjunct to other treatments to boost the immune response. Other molecules (TGF- $\beta$, CCL5, CCR5, toll receptor) found to affect the immune system are also promising. In addition, the development of High-Tech has made some progress in the application of nanotechnology in immunotherapy, mainly as a drug carrier $(137,138)$. In conclusion, although there are many challenges and problems, the possibilities of immunotherapy are endless.

\section{AUTHOR CONTRIBUTIONS}

YD, WZ and LY were responsible for gathering information of the related research and designing the review. XD, DR and FW were responsible for language editing. XQ and JG have contributed to informatio0n interpretation, editing and critical revision of the manuscript. All authors contributed to the article and approved the submitted version.

\section{ACKNOWLEDGMENTS}

Thanks Dr. Weiwei Tang for her advice about the review. 


\section{REFERENCES}

1. Kumar N, Thomas A, Madhu S, Ramos MRD, Shen L, Tan JYH, et al. Analysis of Unplanned Hospital Readmissions Up to 2-Years After Metastatic Spine Tumour Surgery. Eur Spine J Off Publ Eur Spine Society Eur Spinal Deformity Society Eur Section Cervical Spine Res Soc (2021). doi: 10.1007/s00586-021-06723-5

2. Buisman FE, Filipe WF, Kemeny NE, Narayan RR, Srouji RM, Balachandran VP, et al. Recurrence After Liver Resection of Colorectal Liver Metastases: Repeat Resection or Ablation Followed by Hepatic Arterial Infusion Pump Chemotherapy. Ann Surg Oncol (2021) 28(2):808-16. doi: 10.1245/s10434020-08776-0

3. Tomlinson JS, Jarnagin WR, DeMatteo RP, Fong Y, Kornprat P, Gonen M, et al. Actual 10-Year Survival After Resection of Colorectal Liver Metastases Defines Cure. J Clin Oncol Off J Am Soc Clin Oncol (2007) 25(29):4575-80. doi: $10.1200 /$ jco.2007.11.0833

4. Rahbari NN, Birgin E, Bork U, Mehrabi A, Reißfelder C, Weitz J. Anterior Approach vs Conventional Hepatectomy for Resection of Colorectal Liver Metastasis: A Randomized Clinical Trial. JAMA Surg (2021) 156(1):31-40. doi: 10.1001/jamasurg.2020.5050

5. Yasuno M, Uetake H, Ishiguro M, Mizunuma N, Komori T, Miyata G, et al. mFOLFOX6 Plus Bevacizumab to Treat Liver-Only Metastases of Colorectal Cancer That Are Unsuitable for Upfront Resection (TRICC0808): A Multicenter Phase II Trial Comprising the Final Analysis for Survival. Int J Clin Oncol (2019) 24(5):516-25. doi: 10.1007/s10147-018-01393-8

6. Yu X, Zhu L, Liu J, Xie M, Chen J, Li J. Emerging Role of Immunotherapy for Colorectal Cancer With Liver Metastasis. OncoTargets Ther (2020) 13:11645-58. doi: 10.2147/ott.s271955

7. Yang Y, Li X, Ma Z, Wang C, Yang Q, Byrne-Steele M, et al. CTLA-4 Expression by B-1a B Cells is Essential for Immune Tolerance. Nat Commun (2021) 12(1):525. doi: 10.1038/s41467-020-20874-x

8. Le DT, Uram JN, Wang H, Bartlett BR, Kemberling H, Eyring AD, et al. PD1 Blockade in Tumors With Mismatch-Repair Deficiency. New Engl J Med (2015) 372(26):2509-20. doi: 10.1056/NEJMoa1500596

9. Yiemchavee S, Wong-Arce A, Romero-Maldonado A, Shanmugaraj B, Monsivais-Urenda A, Phoolcharoen W, et al. Expression and Immunogenicity Assessment of a Plant-Made Immunogen Targeting the Cytotoxic T-Lymphocyte Associated Antigen-4: A Possible Approach for Cancer Immunotherapy. J Biotechnol (2021) 329:29-37. doi: 10.1016/ j.jbiotec.2021.01.016

10. Wei XL, Luo X, Sheng H, Wang Y, Chen DL, Li JN, et al. PD-L1 Expression in Liver Metastasis: Its Clinical Significance and Discordance With Primary Tumor in Colorectal Cancer. J Trans Med (2020) 18(1):475. doi: 10.1186/ s12967-020-02636-x

11. Hodi FS, O’Day SJ, McDermott DF, Weber RW, Sosman JA, Haanen JB, et al. Improved Survival With Ipilimumab in Patients With Metastatic Melanoma. New Engl J Med (2010) 363(8):711-23. doi: 10.1056/NEJMoa1003466

12. Rizvi NA, Hellmann MD, Snyder A, Kvistborg P, Makarov V, Havel JJ, et al. Cancer Immunology. Mutational Landscape Determines Sensitivity to PD-1 Blockade in Non-Small Cell Lung Cancer. Sci (New York NY) (2015) 348 (6230):124-8. doi: 10.1126/science.aaa1348

13. Malki A, ElRuz RA, Gupta I, Allouch A, Vranic S, Al Moustafa AE. Molecular Mechanisms of Colon Cancer Progression and Metastasis: Recent Insights and Advancements. Int J Mol Sci (2020) 22(1):130. doi: 10.3390/ijms22010130

14. Marmorino F, Boccaccino A, Germani MM, Falcone A, Cremolini C. Immune Checkpoint Inhibitors in pMMR Metastatic Colorectal Cancer: A Tough Challenge. Cancers (2020) 12(8):2317. doi: 10.3390/cancers12082317

15. Jacobi EM, Landon G, Broaddus RR, Roy-Chowdhuri S. Evaluating Mismatch Repair/Microsatellite Instability Status Using Cytology Effusion Specimens to Determine Eligibility for Immunotherapy. Arch Pathol Lab Med (2021) 145(1):46-54. doi: 10.5858/arpa.2019-0398-OA

16. Lichtenstern CR, Ngu RK, Shalapour S, Karin M. Immunotherapy, Inflammation and Colorectal Cancer. Cells (2020) 9(3):618. doi: 10.3390/ cells 9030618

17. Dolcetti R, Viel A, Doglioni C, Russo A, Guidoboni M, Capozzi E, et al. High Prevalence of Activated Intraepithelial Cytotoxic T Lymphocytes and Increased Neoplastic Cell Apoptosis in Colorectal Carcinomas With
Microsatellite Instability. Am J Pathol (1999) 154(6):1805-13 doi: 10.1016/s0002-9440(10)65436-3

18. Bai R, Lv Z, Xu D, Cui J. Predictive Biomarkers for Cancer Immunotherapy With Immune Checkpoint Inhibitors. Biomarker Res (2020) 8:34. doi: 10.1186/s40364-020-00209-0

19. Eng C, Kim TW, Bendell J, Argilés G, Tebbutt NC, Di Bartolomeo M, et al. Atezolizumab With or Without Cobimetinib Versus Regorafenib in Previously Treated Metastatic Colorectal Cancer (IMblaze370): A Multicentre, Open-Label, Phase 3, Randomised, Controlled Trial. Lancet Oncol (2019) 20(6):849-61. doi: 10.1016/s1470-2045(19)30027-0

20. Topalian SL, Hodi FS, Brahmer JR, Gettinger SN, Smith DC, McDermott DF, et al. Safety, Activity, and Immune Correlates of Anti-PD-1 Antibody in Cancer. New Engl J Med (2012) 366(26):2443-54. doi: 10.1056/ NEJMoa1200690

21. Smith CG, Fisher D, Claes B, Maughan TS, Idziaszczyk S, Peuteman G, et al. Somatic Profiling of the Epidermal Growth Factor Receptor Pathway in Tumors From Patients With Advanced Colorectal Cancer Treated With Chemotherapy \pm Cetuximab. Clin Cancer Res an Off J Am Assoc Cancer Res (2013) 19(15):4104-13. doi: 10.1158/1078-0432.ccr-12-2581

22. Venderbosch S, Nagtegaal ID, Maughan TS, Smith CG, Cheadle JP, Fisher D, et al. Mismatch Repair Status and BRAF Mutation Status in Metastatic Colorectal Cancer Patients: A Pooled Analysis of the CAIRO, Cairo2, COIN, and FOCUS Studies. Clin Cancer Res Off J Am Assoc Cancer Res (2014) 20 (20):5322-30. doi: 10.1158/1078-0432.ccr-14-0332

23. Aasebø K, Dragomir A, Sundström M, Mezheyeuski A, Edqvist PH, Eide GE, et al. Consequences of a High Incidence of Microsatellite Instability and BRAF-Mutated Tumors: A Population-Based Cohort of Metastatic Colorectal Cancer Patients. Cancer Med (2019) 8(7):3623-35. doi: $10.1002 / \mathrm{cam} 4.2205$

24. Wang Z, Tang X, Wu X, Yang M, Wang D. Mismatch Repair Status Between Primary Colorectal Tumor and Metastatic Tumor, A Retrospective Consistent Study. Biosci Rep (2019) 39(12):BSR20190730. doi: 10.1042/ bsr20190730

25. Overman MJ, McDermott R, Leach JL, Lonardi S, Lenz HJ, Morse MA, et al. Nivolumab in Patients With Metastatic DNA Mismatch Repair-Deficient or Microsatellite Instability-High Colorectal Cancer (CheckMate 142): An Open-Label, Multicentre, Phase 2 Study. Lancet Oncol (2017) 18(9):118291. doi: 10.1016/s1470-2045(17)30422-9

26. Liu DX, Li DD, He W, Ke CF, Jiang W, Tang JH, et al. PD-1 Blockade in Neoadjuvant Setting of DNA Mismatch Repair-Deficient/Microsatellite Instability-High Colorectal Cancer. Oncoimmunology (2020) 9(1):1711650. doi: 10.1080/2162402x.2020.1711650

27. Brahmer JR, Drake CG, Wollner I, Powderly JD, Picus J, Sharfman WH, et al. Phase I Study of Single-Agent Anti-Programmed Death-1 (MDX-1106) in Refractory Solid Tumors: Safety, Clinical Activity, Pharmacodynamics, and Immunologic Correlates. J Clin Oncol Off J Am Soc Clin Oncol (2010) 28 (19):3167-75. doi: 10.1200/jco.2009.26.7609

28. Chung KY, Gore I, Fong L, Venook A, Beck SB, Dorazio P, et al. Phase II Study of the Anti-Cytotoxic T-Lymphocyte-Associated Antigen 4 Monoclonal Antibody, Tremelimumab, in Patients With Refractory Metastatic Colorectal Cancer. J Clin Oncol Off J Am Soc Clin Oncol (2010) 28(21):3485-90. doi: 10.1200/jco.2010.28.3994

29. Parseghian CM, Patnana M, Bhosale P, Hess KR, Shih YT, Kim B, et al. Evaluating for Pseudoprogression in Colorectal and Pancreatic Tumors Treated With Immunotherapy. J Immunother (Hagerstown Md 1997) (2018) 41(6):284-91. doi: 10.1097/cji.0000000000000222

30. Dierssen JW, de Miranda NF, Ferrone S, van Puijenbroek M, Cornelisse CJ, Fleuren GJ, et al. HNPCC Versus Sporadic Microsatellite-Unstable Colon Cancers Follow Different Routes Toward Loss of HLA Class I Expression. BMC Cancer (2007) 7:33. doi: 10.1186/1471-2407-7-33

31. Xiao W, Ibrahim ML, Redd PS, Klement JD, Lu C, Yang D, et al. Loss of Fas Expression and Function is Coupled With Colon Cancer Resistance to Immune Checkpoint Inhibitor Immunotherapy. Mol Cancer Res MCR (2019) 17(2):420-30. doi: 10.1158/1541-7786.mcr-18-0455

32. Müller CI, Schulmann K, Reinacher-Schick A, Andre N, Arnold D, Tannapfel A, et al. Predictive and Prognostic Value of Microsatellite Instability in Patients With Advanced Colorectal Cancer Treated With a Fluoropyrimidine and Oxaliplatin Containing First-Line Chemotherapy. 
A Report of the AIO Colorectal Study Group. Int J Colorectal Dis (2008) 23 (11):1033-9. doi: 10.1007/s00384-008-0504-2

33. Koopman M, Kortman GA, Mekenkamp L, Ligtenberg MJ, Hoogerbrugge N, Antonini NF, et al. Deficient Mismatch Repair System in Patients With Sporadic Advanced Colorectal Cancer. Br J Cancer (2009) 100(2):266-73. doi: $10.1038 /$ sj.bjc.6604867

34. Overman MJ, Lonardi S, Wong KYM, Lenz HJ, Gelsomino F, Aglietta M, et al. Durable Clinical Benefit With Nivolumab Plus Ipilimumab in DNA Mismatch Repair-Deficient/Microsatellite Instability-High Metastatic Colorectal Cancer. J Clin Oncol Off J Am Soc Clin Oncol (2018) 36(8):7739. doi: 10.1200/jco.2017.76.9901

35. André T, Shiu KK, Kim TW, Jensen BV, Jensen LH, Punt C, et al. Pembrolizumab in Microsatellite-Instability-High Advanced Colorectal Cancer. New Engl J Med (2020) 383(23):2207-18. doi: 10.1056/NEJMoa2017699

36. Kim JH, Kim SY, Baek JY, Cha YJ, Ahn JB, Kim HS, et al. A Phase Ii Study of Avelumab Monotherapy in Patients With Mismatch Repair-Deficient/ Microsatellite Instability-High or POLE-Mutated Metastatic or Unresectable Colorectal Cancer. Cancer Res Treat Off J Korean Cancer Assoc (2020) 52(4):1135-44. doi: 10.4143/crt.2020.218

37. Chen EX, Jonker DJ, Loree JM, Kennecke HF, Berry SR, Couture F, et al. Effect of Combined Immune Checkpoint Inhibition vs Best Supportive Care Alone in Patients With Advanced Colorectal Cancer: The Canadian Cancer Trials Group CO.26 Study. JAMA Oncol (2020) 6(6):831-8. doi: 10.1001/ jamaoncol.2020.0910

38. Ludford K, Cohen R, Svrcek M, Foo WC, Colle R, Parc Y, et al. Pathological Tumor Response Following Immune Checkpoint Blockade for Deficient Mismatch Repair Advanced Colorectal Cancer. J Natl Cancer Institute (2020) 113(2):208-11. doi: 10.1093/jnci/djaa052

39. Cohen R, Hain E, Buhard O, Guilloux A, Bardier A, Kaci R, et al. Association of Primary Resistance to Immune Checkpoint Inhibitors in Metastatic Colorectal Cancer With Misdiagnosis of Microsatellite Instability or Mismatch Repair Deficiency Status. JAMA Oncol (2019) 5(4):551-5. doi: 10.1001/jamaoncol.2018.4942

40. Loupakis F, Maddalena G, Depetris I, Murgioni S, Bergamo F, Dei Tos AP, et al. Treatment With Checkpoint Inhibitors in a Metastatic Colorectal Cancer Patient With Molecular and Immunohistochemical Heterogeneity in MSI/dMMR Status. J Immunother Cancer (2019) 7(1):297. doi: 10.1186/ s40425-019-0788-5

41. Colle R, Radzik A, Cohen R, Pellat A, Lopez-Tabada D, Cachanado M, et al. Pseudoprogression in Patients Treated With Immune Checkpoint Inhibitors for Microsatellite Instability-High/Mismatch Repair-Deficient Metastatic Colorectal Cancer. Eur J Cancer (Oxford Engl 1990) (2020) 144:9-16. doi: 10.1016/j.ejca.2020.11.009

42. Cohen R, Bennouna J, Meurisse A, Tournigand C, de la Fouchardière C, Tougeron D, et al. RECIST and iRECIST Criteria for the Evaluation of Nivolumab Plus Ipilimumab in Patients With Microsatellite InstabilityHigh/Mismatch Repair-Deficient Metastatic Colorectal Cancer: The GERCOR NIPICOL Phase II Study. J Immunother Cancer (2020) 8(2): e001499. doi: 10.1136/jitc-2020-001499

43. Seki N, Brooks AD, Carter CR, Back TC, Parsoneault EM, Smyth MJ, et al. Tumor-Specific CTL Kill Murine Renal Cancer Cells Using Both Perforin and Fas Ligand-Mediated Lysis In Vitro, But Cause Tumor Regression In Vivo in the Absence of Perforin. J Immunol (Baltimore Md 1950) (2002) 168 (7):3484-92. doi: 10.4049/jimmunol.168.7.3484

44. Lavrik IN, Krammer PH. Regulation of CD95/Fas Signaling at the DISC. Cell Death Differentiation (2012) 19(1):36-41. doi: 10.1038/cdd.2011.155

45. Kloor M, Becker C, Benner A, Woerner SM, Gebert J, Ferrone S, et al. Immunoselective Pressure and Human Leukocyte Antigen Class I Antigen Machinery Defects in Microsatellite Unstable Colorectal Cancers. Cancer Res (2005) 65(14):6418-24. doi: 10.1158/0008-5472.can-05-0044

46. Ijsselsteijn ME, Petitprez F, Lacroix L, Ruano D, van der Breggen R, Julie C, et al. Revisiting Immune Escape in Colorectal Cancer in the Era of Immunotherapy. $\mathrm{Br}$ J Cancer (2019) 120(8):815-8. doi: 10.1038/s41416-019-0421-x

47. Ren C, Mai ZJ, Jin Y, He MM, Wang ZQ, Luo HY, et al. Anti-PD-1 Antibody SHR-1210 Plus Apatinib for Metastatic Colorectal Cancer: A Prospective, SingleArm, Open-Label, Phase II Trial. Am J Cancer Res (2020) 10(9):2946-54.

48. Li J, Cong L, Liu J, Peng L, Wang J, Feng A, et al. The Efficacy and Safety of Regorafenib in Combination With Anti-PD-1 Antibody in Refractory
Microsatellite Stable Metastatic Colorectal Cancer: A Retrospective Study. Front Oncol (2020) 10:594125. doi: 10.3389/fonc.2020.594125

49. Wang C, Chevalier D, Saluja J, Sandhu J, Lau C, Fakih M. Regorafenib and Nivolumab or Pembrolizumab Combination and Circulating Tumor DNA Response Assessment in Refractory Microsatellite Stable Colorectal Cancer. Oncologist (2020) 25(8):e1188-94. doi: 10.1634/theoncologist.2020-0161

50. Fukuoka S, Hara H, Takahashi N, Kojima T, Kawazoe A, Asayama M, et al. Regorafenib Plus Nivolumab in Patients With Advanced Gastric or Colorectal Cancer: An Open-Label, Dose-Escalation, and Dose-Expansion Phase Ib Trial (Regonivo, Epoc1603). J Clin Oncol Off J Am Soc Clin Oncol (2020) 38(18):2053-61. doi: 10.1200/jco.19.03296

51. Kawazoe A, Kuboki Y, Shinozaki E, Hara H, Nishina T, Komatsu Y, et al. Multicenter Phase I/II Trial of Napabucasin and Pembrolizumab in Patients With Metastatic Colorectal Cancer (Epoc1503/Scoop Trial). Clin Cancer Res Off J Am Assoc Cancer Res (2020) 26(22):5887-94. doi: 10.1158/10780432.ccr-20-1803

52. Taieb J, Shi Q, Pederson L, Alberts S, Wolmark N, Van Cutsem E, et al. Prognosis of Microsatellite Instability and/or Mismatch Repair Deficiency Stage III Colon Cancer Patients After Disease Recurrence Following Adjuvant Treatment: Results of an ACCENT Pooled Analysis of Seven Studies. Ann Oncol Off J Eur Soc Med Oncol (2019) 30(9):1466-71. doi: 10.1093/annonc/mdz208

53. Martin-Romano P, Ammari S, El-Dakdoukti Y, Baldini C, Varga A, Vuagnat $\mathrm{P}$, et al. Chemotherapy Beyond Immune Checkpoint Inhibitors in Patients With Metastatic Colorectal Cancer. Eur J Cancer (Oxford Engl 1990) (2020) 137:117-26. doi: 10.1016/j.ejca.2020.06.030

54. Newman J, Seetharamu N, Saif MW. Burden of Proof: Evaluating the Efficacy of Tumor Mutational Burden (TMB) in Predicting Response to Immune Checkpoint Inhibitors. Cancer Med J (2020) 3(Suppl 2):17-21.

55. Schrock AB, Ouyang C, Sandhu J, Sokol E, Jin D, Ross JS, et al. Tumor Mutational Burden Is Predictive of Response to Immune Checkpoint Inhibitors in MSI-high Metastatic Colorectal Cancer. Ann Oncol Off J Eur Soc Med Oncol (2019) 30(7):1096-103. doi: 10.1093/annonc/mdz134

56. Fabrizio DA, George TJ Jr, Dunne RF, Frampton G, Sun J, Gowen K, et al. Beyond Microsatellite Testing: Assessment of Tumor Mutational Burden Identifies Subsets of Colorectal Cancer Who May Respond to Immune Checkpoint Inhibition. J Gastrointest Oncol (2018) 9(4):610-7. doi: 10.21037/ jgo.2018.05.06

57. Hirsch D, Gaiser T, Merx K, Weingaertner S, Forster M, Hendricks A, et al. Clinical Responses to PD-1 Inhibition and Their Molecular Characterization in Six Patients With Mismatch Repair-Deficient Metastatic Cancer of the Digestive System. J Cancer Res Clin Oncol (2021) 147(1):263-73. doi: $10.1007 /$ s00432-020-03335-2

58. Llosa NJ, Luber B, Tam AJ, Smith KN, Siegel N, Awan AH, et al. Intratumoral Adaptive Immunosuppression and Type 17 Immunity in Mismatch Repair Proficient Colorectal Tumors. Clin Cancer Res an Off J Am Assoc Cancer Res (2019) 25(17):5250-9. doi: 10.1158/1078-0432.ccr-19-0114

59. Kong JC, Guerra GR, Pham T, Mitchell C, Lynch AC, Warrier SK, et al. Prognostic Impact of Tumor-Infiltrating Lymphocytes in Primary and Metastatic Colorectal Cancer: A Systematic Review and Meta-Analysis. Dis Colon Rectum (2019) 62(4):498-508. doi: 10.1097/dcr.0000000 000001332

60. Loupakis F, Depetris I, Biason P, Intini R, Prete AA, Leone F, et al. Prediction of Benefit From Checkpoint Inhibitors in Mismatch Repair Deficient Metastatic Colorectal Cancer: Role of Tumor Infiltrating Lymphocytes. Oncologist (2020) 25(6):481-7. doi: 10.1634/theoncologist.2019-0611

61. Lu Z, Zhao ZX, Cheng P, Huang F, Guan X, Zhang MG, et al. B7-H3 Immune Checkpoint Expression Is a Poor Prognostic Factor in Colorectal Carcinoma. Modern Pathol Off J U S Can Acad Pathol Inc (2020) 33 (11):2330-40. doi: 10.1038/s41379-020-0587-Z

62. Lu Z, Zou J, Hu Y, Li S, Zhou T, Gong J, et al. Serological Markers Associated With Response to Immune Checkpoint Blockade in Metastatic Gastrointestinal Tract Cancer. JAMA Netw Open (2019) 2(7):e197621. doi: 10.1001/jamanetworkopen.2019.7621

63. Ree AH, Nygaard V, Russnes HG, Heinrich D, Nygaard V, Johansen C, et al. Responsiveness to PD-1 Blockade in End-Stage Colon Cancer With Gene Locus 9p24.1 Copy-Number Gain. Cancer Immunol Res (2019) 7(5):701-6. doi: 10.1158/2326-6066.cir-18-0777 
64. Parkhurst MR, Yang JC, Langan RC, Dudley ME, Nathan DA, Feldman SA, et al. T Cells Targeting Carcinoembryonic Antigen can Mediate Regression of Metastatic Colorectal Cancer But Induce Severe Transient Colitis. Mol Ther J Am Soc Gene Ther (2011) 19(3):620-6. doi: 10.1038/mt.2010.272

65. Zhang C, Wang Z, Yang Z, Wang M, Li S, Li Y, et al. Phase I Escalating-Dose Trial of CAR-T Therapy Targeting Cea(+) Metastatic Colorectal Cancers. Mol Ther J Am Soc Gene Ther (2017) 25(5):1248-58. doi: 10.1016/j.ymthe.2017.03.010

66. Hege KM, Bergsland EK, Fisher GA, Nemunaitis JJ, Warren RS, McArthur JG, et al. Safety, Tumor Trafficking and Immunogenicity of Chimeric Antigen Receptor (CAR)-T Cells Specific for TAG-72 in Colorectal Cancer. J Immunother Cancer (2017) 5:22. doi: 10.1186/s40425-017-0222-9

67. Zhen YH, Liu XH, Yang Y, Li B, Tang JL, Zeng QX, et al. Phase I/II Study of Adjuvant Immunotherapy With Sentinel Lymph Node T Lymphocytes in Patients With Colorectal Cancer. Cancer Immunol Immunother CII (2015) 64(9):1083-93. doi: 10.1007/s00262-015-1715-3

68. Tran E, Robbins PF, Lu YC, Prickett TD, Gartner JJ, Jia L, et al. T-Cell Transfer Therapy Targeting Mutant KRAS in Cancer. New Engl J Med (2016) 375(23):2255-62. doi: 10.1056/NEJMoa1609279

69. Lo W, Parkhurst M, Robbins PF, Tran E, Lu YC, Jia L, et al. Immunologic Recognition of a Shared P53 Mutated Neoantigen in a Patient With Metastatic Colorectal Cancer. Cancer Immunol Res (2019) 7(4):534-43. doi: 10.1158/2326-6066.cir-18-0686

70. Cafri G, Yossef R, Pasetto A, Deniger DC, Lu YC, Parkhurst M, et al. Memory T Cells Targeting Oncogenic Mutations Detected in Peripheral Blood of Epithelial Cancer Patients. Nat Commun (2019) 10(1):449. doi: 10.1038/s41467-019-08304-z

71. Veluchamy JP, Lopez-Lastra S, Spanholtz J, Bohme F, Kok N, Heideman DA, et al. In Vivo Efficacy of Umbilical Cord Blood Stem Cell-Derived NK Cells in the Treatment of Metastatic Colorectal Cancer. Front Immunol (2017) 8:87. doi: $10.3389 /$ fimmu. 2017.00087

72. Xiao L, Cen D, Gan H, Sun Y, Huang N, Xiong H, et al. Adoptive Transfer of NKG2D CAR mRNA-Engineered Natural Killer Cells in Colorectal Cancer Patients. Mol Ther J Am Soc Gene Ther (2019) 27(6):1114-25. doi: 10.1016/ j.ymthe.2019.03.011

73. Li Z, Chi Z, Ang WX, Chen C, Tay JC, Ng YY, et al. Experimental Treatment of Colorectal Cancer in Mice With Human T Cells Electroporated With NKG2D RNA Car. Immunotherapy (2020) 12(10):733-48. doi: 10.2217/imt2019-0137

74. Gatti-Mays ME, Strauss J, Donahue RN, Palena C, Del Rivero J, Redman JM, et al. A Phase I Dose-Escalation Trial of BN-CV301, a Recombinant Poxviral Vaccine Targeting MUC1 and CEA With Costimulatory Molecules. Clin Cancer Res an Off J Am Assoc Cancer Res (2019) 25(16):4933-44. doi: 10.1158/1078-0432.ccr-19-0183

75. Speetjens FM, Kuppen PJ, Welters MJ, Essahsah F, Voet van den Brink AM, Lantrua MG, et al. Induction of p53-Specific Immunity by a p 53 Synthetic Long Peptide Vaccine in Patients Treated for Metastatic Colorectal Cancer. Clin Cancer Res an Off J Am Assoc Cancer Res (2009) 15(3):1086-95. doi: 10.1158/1078-0432.ccr-08-2227

76. Morse MA, Hobeika AC, Osada T, Berglund P, Hubby B, Negri S, et al. An Alphavirus Vector Overcomes the Presence of Neutralizing Antibodies and Elevated Numbers of Tregs to Induce Immune Responses in Humans With Advanced Cancer. J Clin Invest (2010) 120(9):3234-41. doi: 10.1172/jci42672

77. Gulley JL, Arlen PM, Tsang KY, Yokokawa J, Palena C, Poole DJ, et al. Pilot Study of Vaccination With Recombinant CEA-MUC-1-TRICOM PoxviralBased Vaccines in Patients With Metastatic Carcinoma. Clin Cancer Res Off J Am Assoc Cancer Res (2008) 14(10):3060-9. doi: 10.1158/1078-0432.ccr-080126

78. Morse MA, Niedzwiecki D, Marshall JL, Garrett C, Chang DZ, Aklilu M, et al. A Randomized Phase II Study of Immunization With Dendritic Cells Modified With Poxvectors Encoding CEA and MUC1 Compared With the Same Poxvectors Plus GM-CSF for Resected Metastatic Colorectal Cancer. Ann Surg (2013) 258(6):879-86. doi: 10.1097/SLA.0b013e318292919e

79. Balint JP, Gabitzsch ES, Rice A, Latchman Y, Xu Y, Messerschmidt GL, et al. Extended Evaluation of a Phase 1/2 Trial on Dosing, Safety, Immunogenicity, and Overall Survival After Immunizations With an Advanced-Generation Ad5 [E1-, E2b-]-CEA(6D) Vaccine in Late-Stage Colorectal Cancer. Cancer Immunol Immunother CII (2015) 64(8):977-87. doi: 10.1007/s00262-015-1706-4
80. Crosby EJ, Hobeika AC, Niedzwiecki D, Rushing C, Hsu D, Berglund P, et al. Long-Term Survival of Patients With Stage III Colon Cancer Treated With VRP-CEA(6D), an Alphavirus Vector That Increases the CD8+ Effector Memory T Cell to Treg Ratio. J Immunother Cancer (2020) 8(2):e001662. doi: $10.1136 /$ jitc-2020-001662

81. Scurr M, Pembroke T, Bloom A, Roberts D, Thomson A, Smart K, et al. Effect of Modified Vaccinia Ankara-5T4 and Low-Dose Cyclophosphamide on Antitumor Immunity in Metastatic Colorectal Cancer: A Randomized Clinical Trial. JAMA Oncol (2017) 3(10):e172579. doi: 10.1001/ jamaoncol.2017.2579

82. Schimanski CC, Kasper S, Hegewisch-Becker S, Schröder J, Overkamp F, Kullmann F, et al. Adjuvant MUC Vaccination With Tecemotide After Resection of Colorectal Liver Metastases: A Randomized, Double-Blind, Placebo-Controlled, Multicenter AIO Phase II Trial (LICC). Oncoimmunology (2020) 9(1):1806680. doi: 10.1080/2162402x.2020.1806680

83. Kloor M, Reuschenbach M, Pauligk C, Karbach J, Rafiyan MR, Al-Batran SE, et al. A Frameshift Peptide Neoantigen-Based Vaccine for Mismatch RepairDeficient Cancers: A Phase I/IIa Clinical Trial. Clin Cancer Res an Off J Am Assoc Cancer Res (2020) 26(17):4503-10. doi: 10.1158/1078-0432.ccr-19-3517

84. Kaufman HL, Lenz HJ, Marshall J, Singh D, Garett C, Cripps C, et al. Combination Chemotherapy and ALVAC-CEA/B7.1 Vaccine in Patients With Metastatic Colorectal Cancer. Clin Cancer Res an Off J Am Assoc Cancer Res (2008) 14(15):4843-9. doi: 10.1158/1078-0432.ccr-08-0276

85. Harrop R, Drury N, Shingler W, Chikoti P, Redchenko I, Carroll MW, et al. Vaccination of Colorectal Cancer Patients With TroVax Given Alongside Chemotherapy (5-Fluorouracil, Leukovorin and Irinotecan) is Safe and Induces Potent Immune Responses. Cancer Immunol Immunother CII (2008) 57(7):977-86. doi: 10.1007/s00262-007-0428-7

86. Murahashi M, Hijikata Y, Yamada K, Tanaka Y, Kishimoto J, Inoue H, et al. Phase I Clinical Trial of a Five-Peptide Cancer Vaccine Combined With Cyclophosphamide in Advanced Solid Tumors. Clin Immunol (Orlando Fla) (2016) 166-167:48-58. doi: 10.1016/j.clim.2016.03.015

87. Kawamura J, Sugiura F, Sukegawa Y, Yoshioka Y, Hida JI, Hazama S, et al. Multicenter, Phase II Clinical Trial of Peptide Vaccination With Oral Chemotherapy Following Curative Resection for Stage III Colorectal Cancer. Oncol Lett (2018) 15(4):4241-7. doi: 10.3892/ol.2018.7905

88. Barth RJJr., Fisher DA, Wallace PK, Channon JY, Noelle RJ, Gui J, et al. A Randomized Trial of Ex Vivo CD40L Activation of a Dendritic Cell Vaccine in Colorectal Cancer Patients: Tumor-Specific Immune Responses are Associated With Improved Survival. Clin Cancer Res an Off J Am Assoc Cancer Res (2010) 16(22):5548-56. doi: 10.1158/1078-0432.ccr-10-2138

89. Caballero-Baños M, Benitez-Ribas D, Tabera J, Varea S, Vilana R, Bianchi L, et al. Phase II Randomised Trial of Autologous Tumour Lysate Dendritic Cell Plus Best Supportive Care Compared With Best Supportive Care in PreTreated Advanced Colorectal Cancer Patients. Eur J Cancer (Oxford Engl 1990) (2016) 64:167-74. doi: 10.1016/j.ejca.2016.06.008

90. Rodriguez J, Castañón E, Perez-Gracia JL, Rodriguez I, Viudez A, Alfaro C, et al. A Randomized Phase II Clinical Trial of Dendritic Cell Vaccination Following Complete Resection of Colon Cancer Liver Metastasis. J Immunother Cancer (2018) 6(1):96. doi: 10.1186/s40425-018-0405-Z

91. Liu KJ, Chao TY, Chang JY, Cheng AL, Ch'ang HJ, Kao WY, et al. A Phase I Clinical Study of Immunotherapy for Advanced Colorectal Cancers Using Carcinoembryonic Antigen-Pulsed Dendritic Cells Mixed With Tetanus Toxoid and Subsequent IL-2 Treatment. J Biomed Sci (2016) 23(1):64. doi: 10.1186/s12929-016-0279-7

92. Shimodaira S, Sano K, Hirabayashi K, Koya T, Higuchi Y, Mizuno Y, et al. Dendritic Cell-Based Adjuvant Vaccination Targeting Wilms' Tumor 1 in Patients With Advanced Colorectal Cancer. Vaccines (2015) 3(4):1004-18. doi: $10.3390 /$ vaccines 3041004

93. Flickinger JC Jr, Singh J, Carlson R, Leong E, Baybutt TR, Barton J, et al. Chimeric Ad5.F35 Vector Evades Anti-Adenovirus Serotype 5 Neutralization Opposing GUCY2C-Targeted Antitumor Immunity. J Immunother Cancer (2020) 8(2):e001046. doi: 10.1136/jitc-2020-001046

94. Manzoni M, Rovati B, Ronzoni M, Loupakis F, Mariucci S, Ricci V, et al. Immunological Effects of Bevacizumab-Based Treatment in Metastatic Colorectal Cancer. Oncology (2010) 79(3-4):187-96. doi: 10.1159/000320609

95. Inoue Y, Hazama S, Suzuki N, Tokumitsu Y, Kanekiyo S, Tomochika S, et al. Cetuximab Strongly Enhances Immune Cell Infiltration Into Liver 
Metastatic Sites in Colorectal Cancer. Cancer Sci (2017) 108(3):455-60. doi: $10.1111 /$ cas.13162

96. Troiani T, Martinelli E, Ciardiello D, Zanaletti N, Cardone C, Borrelli C, et al. Phase II Study of Avelumab in Combination With Cetuximab in PreTreated RAS Wild-Type Metastatic Colorectal Cancer Patients: CAVE (Cetuximab-Avelumab) Colon. J Clin Oncol (2019) 37(4_suppl):TPS731TPS. doi: 10.1200/JCO.2019.37.4_suppl.TPS731

97. Stein A, Binder M, Goekkurt E, Lorenzen S, Riera-Knorrenschild J, Depenbusch R, et al. Avelumab and Cetuximab in Combination With FOLFOX in Patients With Previously Untreated Metastatic Colorectal Cancer (MCRC): Final Results of the Phase II AVETUX Trial (AIO-KRK-0216). J Clin Oncol (2020) 38(4_suppl):96-. doi: 10.1200/JCO.2020.38.4_suppl.96

98. Grothey A, Tabernero J, Arnold D, De Gramont A, Ducreux MP, O’Dwyer $\mathrm{PJ}$, et al. Fluoropyrimidine (FP) + Bevacizumab (BEV) + Atezolizumab vs FP/BEV in BRAFwt Metastatic Colorectal Cancer (MCRC): Findings From Cohort 2 of MODUL - A Multicentre, Randomized Trial of BiomarkerDriven Maintenance Treatment Following First-Line Induction Therapy. Ann Oncol (2018) 29:viii714-5. doi: 10.1093/annonc/mdy424.020

99. Hellmann MD, Kim TW, Lee CB, Goh BC, Miller WH Jr, Oh DY, et al. Phase Ib Study of Atezolizumab Combined With Cobimetinib in Patients With Solid Tumors. Ann Oncol Off J Eur Soc Med Oncol (2019) 30(7):113442. doi: 10.1093/annonc/mdz113

100. Chen S, Li X, Chen R, Yin M, Zheng Q. Cetuximab Intensifies the ADCC Activity of Adoptive NK Cells in a Nude Mouse Colorectal Cancer Xenograft Model. Oncol Lett (2016) 12(3):1868-76. doi: 10.3892/ol.2016.4835

101. Veluchamy JP, Spanholtz J, Tordoir M, Thijssen VL, Heideman DA, Verheul $\mathrm{HM}$, et al. Combination of NK Cells and Cetuximab to Enhance Anti-Tumor Responses in RAS Mutant Metastatic Colorectal Cancer. PloS One (2016) 11 (6):e0157830. doi: 10.1371/journal.pone.0157830

102. Correale P, Cusi MG, Tsang KY, Del Vecchio MT, Marsili S, Placa ML, et al. Chemo-Immunotherapy of Metastatic Colorectal Carcinoma With Gemcitabine Plus FOLFOX 4 Followed by Subcutaneous Granulocyte Macrophage Colony-Stimulating Factor and Interleukin-2 Induces Strong Immunologic and Antitumor Activity in Metastatic Colon Cancer Patients. J Clin Oncol Off J Am Soc Clin Oncol (2005) 23(35):8950-8. doi: 10.1200/ jco.2005.12.147

103. Correale P, Tagliaferri P, Fioravanti A, Del Vecchio MT, Remondo C, Montagnani F, et al. Immunity Feedback and Clinical Outcome in Colon Cancer Patients Undergoing Chemoimmunotherapy With Gemcitabine + FOLFOX Followed by Subcutaneous Granulocyte Macrophage ColonyStimulating Factor and Aldesleukin (GOLFIG-1 Trial). Clin Cancer Res an Off J Am Assoc Cancer Res (2008) 14(13):4192-9. doi: 10.1158/10780432.ccr-07-5278

104. Correale P, Botta C, Rotundo MS, Guglielmo A, Conca R, Licchetta A, et al. Gemcitabine, Oxaliplatin, Levofolinate, 5-Fluorouracil, GranulocyteMacrophage Colony-Stimulating Factor, and Interleukin-2 (GOLFIG) Versus FOLFOX Chemotherapy in Metastatic Colorectal Cancer Patients: The GOLFIG-2 Multicentric Open-Label Randomized Phase III Trial. J Immunother (Hagerstown Md 1997) (2014) 37(1):26-35. doi: 10.1097/ cji.0000000000000004

105. Caraglia M, Correale P, Giannicola R, Staropoli N, Botta C, Pastina P, et al. GOLFIG Chemo-Immunotherapy in Metastatic Colorectal Cancer Patients. A Critical Review on a Long-Lasting Follow-Up. Front Oncol (2019) 9:1102. doi: $10.3389 /$ fonc. 2019.01102

106. Roselli M, Formica V, Cereda V, Jochems C, Richards J, Grenga I, et al. The Association of Clinical Outcome and Peripheral T-Cell Subsets in Metastatic Colorectal Cancer Patients Receiving First-Line FOLFIRI Plus Bevacizumab Therapy. Oncoimmunology (2016) 5(7):e1188243. doi: 10.1080/2162402x. 2016.1188243

107. Scurr M, Pembroke T, Bloom A, Roberts D, Thomson A, Smart K, et al. LowDose Cyclophosphamide Induces Antitumor T-Cell Responses, Which Associate With Survival in Metastatic Colorectal Cancer. Clin Cancer Res Off J Am Assoc Cancer Res (2017) 23(22):6771-80. doi: 10.1158/10780432.ccr-17-0895

108. Dagenborg VJ, Marshall SE, Yaqub S, Grzyb K, Boye K, Lund-Iversen M, et al. Neoadjuvant Chemotherapy Is Associated With a Transient Increase of Intratumoral T-Cell Density in Microsatellite Stable Colorectal Liver Metastases. Cancer Biol Ther (2020) 21(5):432-40. doi: 10.1080/15384047.2020.1721252
109. Huang KC, Chiang SF, Chen WT, Chen TW, Hu CH, Yang PC, et al. Decitabine Augments Chemotherapy-Induced PD-L1 Upregulation for PDL1 Blockade in Colorectal Cancer. Cancers (2020) 12(2):462. doi: 10.3390/ cancers 12020462

110. Dosset M, Vargas TR, Lagrange A, Boidot R, Végran F, Roussey A, et al. PD1/PD-L1 Pathway: An Adaptive Immune Resistance Mechanism to Immunogenic Chemotherapy in Colorectal Cancer. Oncoimmunology (2018) 7(6):e1433981. doi: 10.1080/2162402x.2018.1433981

111. Bruni E, Cazzetta V, Donadon M, Cimino M, Torzilli G, Spata G, et al. Chemotherapy Accelerates Immune-Senescence and Functional Impairments of V $\delta 2$ (Pos) T Cells in Elderly Patients Affected by Liver Metastatic Colorectal Cancer. J Immunother Cancer (2019) 7(1):347. doi: 10.1186/s40425-019-0825-4

112. Floudas CS, Brar G, Mabry-Hrones D, Duffy AG, Wood B, Levy E, et al. A Pilot Study of the PD-1 Targeting Agent Amp-224 Used With Low-Dose Cyclophosphamide and Stereotactic Body Radiation Therapy in Patients With Metastatic Colorectal Cancer. Clin Colorectal Cancer (2019) 18(4): e349-60. doi: 10.1016/j.clcc.2019.06.004

113. Dunne PD, McArt DG, O’Reilly PG, Coleman HG, Allen WL, Loughrey M, et al. Immune-Derived PD-L1 Gene Expression Defines a Subgroup of Stage Ii/Iii Colorectal Cancer Patients With Favorable Prognosis Who May Be Harmed by Adjuvant Chemotherapy. Cancer Immunol Res (2016) 4(7):58291. doi: 10.1158/2326-6066.cir-15-0302

114. Shi L, Wang J, Ding N, Zhang Y, Zhu Y, Dong S, et al. Inflammation Induced by Incomplete Radiofrequency Ablation Accelerates Tumor Progression and Hinders PD-1 Immunotherapy. Nat Commun (2019) 10(1):5421. doi: 10.1038/s41467-019-13204-3

115. Lemdani K, Mignet N, Boudy V, Seguin J, Oujagir E, Bawa O, et al. Local Immunomodulation Combined to Radiofrequency Ablation Results in a Complete Cure of Local and Distant Colorectal Carcinoma. Oncoimmunology (2019) 8(3):1550342. doi: 10.1080/2162402x.2018.1550342

116. Löffler MW, Nussbaum B, Jäger G, Jurmeister PS, Budczies J, Pereira PL, et al. A Non-Interventional Clinical Trial Assessing Immune Responses After Radiofrequency Ablation of Liver Metastases From Colorectal Cancer. Front Immunol (2019) 10:2526. doi: 10.3389/fimmu.2019.02526

117. Shi L, Chen L, Wu C, Zhu Y, Xu B, Zheng X, et al. PD-1 Blockade Boosts Radiofrequency Ablation-Elicited Adaptive Immune Responses Against Tumor. Clin Cancer Res an Off J Am Assoc Cancer Res (2016) 22(5):117384. doi: 10.1158/1078-0432.ccr-15-1352

118. Liersch T, Meller J, Kulle B, Behr TM, Markus P, Langer C, et al. Phase II Trial of Carcinoembryonic Antigen Radioimmunotherapy With 131ILabetuzumab After Salvage Resection of Colorectal Metastases in the Liver: Five-Year Safety and Efficacy Results. J Clin Oncol Off J Am Soc Clin Oncol (2005) 23(27):6763-70. doi: 10.1200/jco.2005.18.622

119. Liersch T, Meller J, Bittrich M, Kulle B, Becker H, Goldenberg DM. Update of Carcinoembryonic Antigen Radioimmunotherapy With (131)ILabetuzumab After Salvage Resection of Colorectal Liver Metastases: Comparison of Outcome to a Contemporaneous Control Group. Ann Surg Oncol (2007) 14(9):2577-90. doi: 10.1245/s10434-006-9328-x

120. Ychou M, Azria D, Menkarios C, Faurous P, Quenet F, Saint-Aubert B, et al. Adjuvant Radioimmunotherapy Trial With iodine-131-labeled AntiCarcinoembryonic Antigen Monoclonal Antibody F6 F(Ab')2 After Resection of Liver Metastases From Colorectal Cancer. Clin Cancer Res Off J Am Assoc Cancer Res (2008) 14(11):3487-93. doi: 10.1158/1078-0432.ccr07-4698

121. Herbertson RA, Tebbutt NC, Lee FT, Gill S, Chappell B, Cavicchiolo T, et al Targeted Chemoradiation in Metastatic Colorectal Cancer: A Phase I Trial of 131I-huA33 With Concurrent Capecitabine. J Nucl Med Off Publication Soc Nucl Med (2014) 55(4):534-9. doi: 10.2967/jnumed.113.132761

122. Vassileva V, Rajkumar V, Mazzantini M, Robson M, Badar A, Sharma S, et al. Significant Therapeutic Efficacy With Combined Radioimmunotherapy and Cetuximab in Preclinical Models of Colorectal Cancer. J Nucl Med Off Publication Soc Nucl Med (2015) 56(8):1239-45. doi: 10.2967/ jnumed.115.157362

123. Chen $\mathrm{H}$, Zhao L, Fu K, Lin Q, Wen X, Jacobson O, et al. Integrin $\alpha(V) \beta(3)$ Targeted Radionuclide Therapy Combined With Immune Checkpoint Blockade Immunotherapy Synergistically Enhances Anti-Tumor Efficacy. Theranostics (2019) 9(25):7948-60. doi: 10.7150/thno.39203 
124. Liu S, Ren J, Ten Dijke P. Targeting Tgf $\beta$ Signal Transduction for Cancer Therapy. Signal Transduct Targeted Ther (2021) 6(1):8. doi: 10.1038/s41392020-00436-9

125. Xie YH, Chen YX, Fang JY. Comprehensive Review of Targeted Therapy for Colorectal Cancer. Signal Transduct Targeted Ther (2020) 5(1):22. doi: 10.1038/s41392-020-0116-Z

126. Tauriello DVF, Palomo-Ponce S, Stork D, Berenguer-Llergo A, BadiaRamentol J, Iglesias M, et al. Tgf $\beta$ Drives Immune Evasion in Genetically Reconstituted Colon Cancer Metastasis. Nature (2018) 554(7693):538-43. doi: 10.1038/nature25492

127. Korbecki J, Grochans S, Gutowska I, Barczak K, Baranowska-Bosiacka I. Cc Chemokines in a Tumor: A Review of Pro-Cancer and Anti-Cancer Properties of Receptors Ccr5, CCR6, Ccr7, CCR8, CCR9, and CCR10 Ligands. Int J Mol Sci (2020) 21(20):7619. doi: 10.3390/ijms21207619

128. Halama N, Zoernig I, Berthel A, Kahlert C, Klupp F, Suarez-Carmona M, et al. Tumoral Immune Cell Exploitation in Colorectal Cancer Metastases Can Be Targeted Effectively by Anti-CCR5 Therapy in Cancer Patients. Cancer Cell (2016) 29(4):587-601. doi: 10.1016/j.ccell.2016.03.005

129. Zhang S, Zhong M, Wang C, Xu Y, Gao WQ, Zhang Y. CCL5-Deficiency Enhances Intratumoral Infiltration of CD8(+) T Cells in Colorectal Cancer. Cell Death Dis (2018) 9(7):766. doi: 10.1038/s41419-018-0796-2

130. Suarez-Carmona M, Chaorentong P, Kather JN, Rothenheber R, Ahmed A, Berthel A, et al. CCR5 Status and Metastatic Progression in Colorectal Cancer. Oncoimmunology (2019) 8(9):e1626193. doi: 10.1080/2162402x.2019.1626193

131. Kanzler H, Barrat FJ, Hessel EM, Coffman RL. Therapeutic Targeting of Innate Immunity With Toll-Like Receptor Agonists and Antagonists. Nat Med (2007) 13(5):552-9. doi: 10.1038/nm1589

132. Weihrauch MR, Richly H, von Bergwelt-Baildon MS, Becker HJ, Schmidt M, Hacker UT, et al. Phase I Clinical Study of the Toll-Like Receptor 9 Agonist MGN1703 in Patients With Metastatic Solid Tumours. Eur J Cancer (Oxford Engl 1990) (2015) 51(2):146-56. doi: 10.1016/j.ejca.2014.11.002

133. Sorski L, Melamed R, Levi B, Matzner P, Lavon H, Rosenne E, et al. Prevention of Liver Metastases Through Perioperative Acute CpG-C
Immune Stimulation. Cancer Immunol Immunother CII (2020) 69 (10):2021-31. doi: 10.1007/s00262-020-02596-7

134. Brackett CM, Kojouharov B, Veith J, Greene KF, Burdelya LG, Gollnick SO, et al. Toll-Like Receptor-5 Agonist, Entolimod, Suppresses Metastasis and Induces Immunity by Stimulating an NK-Dendritic-CD8+ T-Cell Axis. Proc Natl Acad Sci USA (2016) 113(7):E874-83. doi: 10.1073/pnas. 1521359113

135. Zheng JH, Nguyen VH, Jiang SN, Park SH, Tan W, Hong SH, et al. Two-Step Enhanced Cancer Immunotherapy With Engineered Salmonella Typhimurium Secreting Heterologous Flagellin. Sci Trans Med (2017) 9 (376):eaak9537. doi: 10.1126/scitranslmed.aak9537

136. Cohen R, Pudlarz T, Delattre JF, Colle R, André T. Molecular Targets for the Treatment of Metastatic Colorectal Cancer. Cancers (2020) 12(9):2350. doi: 10.3390/cancers 12092350

137. Feng B, Zhou F, Hou B, Wang D, Wang T, Fu Y, et al. Binary Cooperative Prodrug Nanoparticles Improve Immunotherapy by Synergistically Modulating Immune Tumor Microenvironment. Advanced Mater (Deerfield Beach Fla) (2018) 30(38):e1803001. doi: 10.1002/adma.201803001

138. Qi X, Liu X, Matiski L, Rodriguez Del Villar R, Yip T, Zhang F, et al. Rna Origami Nanostructures for Potent and Safe Anticancer Immunotherapy. ACS nano (2020) 14(4):4727-40. doi: 10.1021/acsnano.0c00602

Conflict of Interest: The authors declare that the research was conducted in the absence of any commercial or financial relationships that could be construed as a potential conflict of interest.

Copyright (c) 2021 Dai, Zhao, Yue, Dai, Rong, Wu, Gu and Qian. This is an openaccess article distributed under the terms of the Creative Commons Attribution License (CC BY). The use, distribution or reproduction in other forums is permitted, provided the original author(s) and the copyright owner(s) are credited and that the original publication in this journal is cited, in accordance with accepted academic practice. No use, distribution or reproduction is permitted which does not comply with these terms. 